\title{
THE
}

\section{How well does wind speed predict air-sea gas transfer in the sea ice zone? A synthesis of radon deficit profiles in the upper water column of the Arctic Ocean}

\author{
Brice Loose \\ University of Rhode Island, bloose@uri.edu \\ Roger P. Kelly \\ University of Rhode Island, rokelly@uri.edu
}

\author{
A. Bigdeli \\ University of Rhode Island \\ W. Williams \\ M. Rutgers van der Loeff
}

See next page for additional authors

Follow this and additional works at: https://digitalcommons.uri.edu/gsofacpubs

Terms of Use

All rights reserved under copyright.

\section{Citation/Publisher Attribution}

Loose, B., R. P. Kelly, A. Bigdeli, W. Williams, R. Krishfield, M. Rutgers van der Loeff, and S. B. Moran (2017), How well does wind speed predict air-sea gas transfer in the sea ice zone? A synthesis of radon deficit profiles in the upper water column of the Arctic Ocean, J. Geophys. Res. Oceans, 122, 3696-3714, doi:10.1002/2016JC012460.

Available at: https://doi.org/10.1002/2016JC012460

This Article is brought to you for free and open access by the Graduate School of Oceanography at DigitalCommons@URI. It has been accepted for inclusion in Graduate School of Oceanography Faculty Publications by an authorized administrator of DigitalCommons@URI. For more information, please contact digitalcommons-group@uri.edu. 


\section{Authors}

Brice Loose, Roger P. Kelly, A. Bigdeli, W. Williams, M. Rutgers van der Loeff, and S. B. Moran 


\section{Journal of Geophysical Research: Oceans}

\section{RESEARCH ARTICLE \\ 10.1002/2016JC012460 \\ Key Points: \\ How well does wind speed predict air-sea gas transfer in the sea ice zone? A synthesis of radon deficit profiles in the upper water column of the Arctic Ocean}

-We present previously overlooked details related to gas tracer budgets in the presence of sea ice

- Radon-deficit estimates of $\mathrm{k}$ show statistically adequate fit to wind speed parameterizations, when measured in $100 \%$ open water

- Radon-deficit estimates of $k$ do not fit with wind speed parameterizations, when measured beneath sea ice cover

Supporting Information: - Supporting Information S1 - Data Set S1

Correspondence to:

B. Loose,

brice@gso.uri.edu

\section{Citation:}

Loose, B., R. P. Kelly, A. Bigdeli, W. Williams, R. Krishfield, M. Rutgers van der Loeff, and S. B. Moran (2017), How well does wind speed predict air-sea gas transfer in the sea ice zone? A synthesis of radon deficit profiles in the upper water column of the Arctic Ocean, J. Geophys. Res. Oceans, 122, 3696-3714, doi:10.1002/

2016JC012460.

Received 10 OCT 2016

Accepted 31 JAN 2017

Accepted article online 7 FEB 2017

Published online 5 MAY 2017

B. Loose1 ${ }^{1 D}$, R. P. Kelly ${ }^{(D)}$, A. Bigdeli1', W. Williams², R. Krishfield³ ${ }^{(D)}$, M. Rutgers van der Loeff ${ }^{4}$, and S. B. Moran5 (D)

${ }^{1}$ University of Rhode Island, Graduate School of Oceanography, Narragansett, Rhode Island, USA, ${ }^{2}$ Fisheries and Oceans Canada, Institute of Ocean Sciences, Sidney, British Columbia, Canada, ${ }^{3}$ Woods Hole Oceanographic Institution, Marine Marine Research, Bremerhaven, Germany, ${ }^{5}$ College of Fisheries and Ocean Sciences, University of Alaska Fairbanks, Fairbanks, Alaska, USA

Plain Language Summary This study shows how the rate of gas exchange between the ocean but here we present 58 published estimates and synthesize what they can tell us. This rate is relevant to Chemistry and Geochemistry, Woods Hole, Massachusetts, USA, ${ }^{4}$ Alfred Wegener Institute, Helmholtz Center for Polar and

\begin{abstract}
We present 34 profiles of radon-deficit from the ice-ocean boundary layer of the Beaufort Sea. Including these 34, there are presently 58 published radon-deficit estimates of air-sea gas transfer velocity $(k)$ in the Arctic Ocean; 52 of these estimates were derived from water covered by $10 \%$ sea ice or more. The average value of $k$ collected since 2011 is $4.0 \pm 1.2 \mathrm{~m} \mathrm{~d}^{-1}$. This exceeds the quadratic wind speed prediction of weighted $k_{w s}=2.85 \mathrm{~m} \mathrm{~d}^{-1}$ with mean-weighted wind speed of $6.4 \mathrm{~m} \mathrm{~s}^{-1}$. We show how ice cover changes the mixed-layer radon budget, and yields an "effective gas transfer velocity." We use these 58 estimates to statistically evaluate the suitability of a wind speed parameterization for $k$, when the ocean surface is ice covered. Whereas the six profiles taken from the open ocean indicate a statistically good fit to wind speed parameterizations, the same parameterizations could not reproduce $k$ from the sea ice zone. We conclude that techniques for estimating $k$ in the open ocean cannot be similarly applied to determine $k$ in the presence of sea ice. The magnitude of $k$ through gaps in the ice may reach high values as ice cover increases, possibly as a result of focused turbulence dissipation at openings in the free surface. These 58 profiles are presently the most complete set of estimates of $k$ across seasons and variable ice cover; as dissolved tracer budgets they reflect air-sea gas exchange with no impact from air-ice gas exchange.
\end{abstract} and atmosphere can be affected by the presence of sea ice. The rate of gas exchange is difficult to measure, ocean and atmosphere budgets of methane, carbon dioxide, and other greenhouse gases.

\section{Introduction}

There is pressing motivation to improve our ability to estimate fluxes at the air-ice-ocean interface of the Arctic Ocean, including heat fluxes [Maslowski et al., 2000], freshwater fluxes [Morison et al., 2012], aerosol production [Heintzenberg et al., 2015], and gas fluxes [Bates, 2006]. These processes arise as a result of the unique physics and biogeochemistry in the ice-ocean boundary layer (IOBL), but their rate of flux is typically determined by the magnitude of turbulence forcing that occurs close to the boundary. Therefore, we require measurements of both the gradients and the forcing.

The methods for measuring air-sea gas fluxes can be categorized as: (1) accumulation, gradient, or perturbation measurements above the air-sea interface [Edson et al., 1998], and (2) gas budget or gas ratio measurements in the water below the air-sea interface [Nightingale et al., 2000; Loose and Schlosser, 2011]. The most powerful experiments have been those where gas exchange are measured using both approaches [ $\mathrm{Ho}$ et al., 2011a]. However, in the ice-covered ocean, these two approaches measure fundamentally different fluxes, because sea ice, in addition to seawater, is recognized as a potential source or sink for atmospheric gases, depending on the season [Zemmelink et al., 2008; Nomura et al., 2010; Delille et al., 2014]. Studies (c) 2017. American Geophysical Union. All Rights Reserved. 


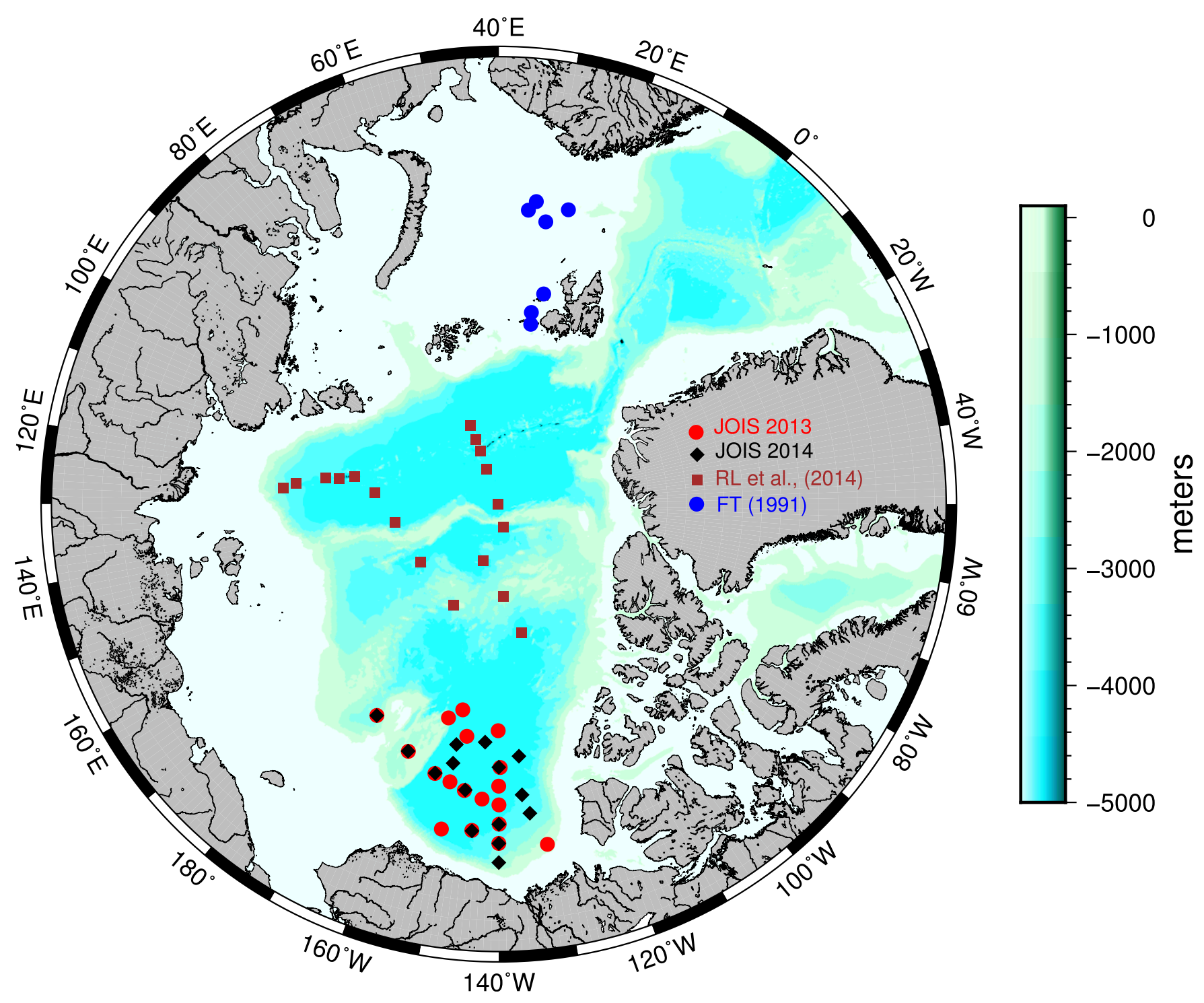

Figure 1. Map of the radon-deficit station locations for this study (JOIS 2013 and 2014) and the locations of previous radon-deficit profiles that were also included in this study analysis [Rutgers Van Der Loeff et al., 2014] and [Fanning and Torres, 1991].

have attempted to determine the kinetics of gas transfer by measuring the atmospheric flux [Else et al., 2011; Butterworth and Miller, 2016]; however, the imprint of atmospheric measurements includes both ice and water, and it is consequently difficult to distinguish the influence of these two gas reservoirs without measuring both fluxes directly.

The second approach-exploiting a gas budget or gas ratio measurements in the ocean mixed-layer-can present significant technical challenges. The so-called dual tracer approach, where the ratio of two introduced gas tracers are measured over time, has been fruitful in many regions of the ocean [Stanley et al., 2009; Ho et al., 2011b], but requires a major logistical effort to follow the tracers in the surface ocean. To date, this method has not been utilized in ice-covered waters.

In contrast, the geochemical tracers radon-222 and radium-226 have found renewed interest for their utility in estimating air-sea gas exchange in polar regions. The significant advantage that these tracers have over other methods is the relative efficacy involved in making a single estimate of $k$ : A single water-column profile of radon/radium yields an estimate of air-sea gas exchange. For these reasons, the radon-deficit method is an attractive approach, and was used during the GEOSECS era to yield some of the first measurements of 
$k$ for the open ocean [Broecker and Peng, 1971; Peng et al., 1979]. The principle disadvantage of this method, however, has been in the difficulty of interpreting the profiles and finding good agreement between perceived forcing by turbulence and the magnitude of $k$ [Smethie et al., 1985; Bender et al., 2011].

In this study, we provide (1) a synthesis of estimates of $k$ derived using 24 profiles of the radon-deficit from prior studies in the Barents Sea [Fanning and Torres, 1991] and Eurasian Bain [Rutgers Van Der Loeff et al., 2014], and (2) 34 new radon/radium profiles collected during August 2013, and October 2014, aboard the CCGS Louis S. St. Laurent in the Canada Basin (Figure 1). Collectively, these measurements compose a PanArctic data set of transfer velocities over four nonconsecutive years, across a spectrum of seasonal forcing and sea ice cover conditions. These estimates of $k$ provide an opportunity to estimate the average transfer kinetics and to evaluate the dependency with parameters such as percent ice cover and rate of wind speed forcing-two of the principal diagnostic variables for air-sea exchange processes.

\section{Methods}

\subsection{Interpretation of Radon and Radium in the IOBL}

There are two distinguishing characteristics of the IOBL that require a unique interpretation of the dissolved-gas budgets when compared to the open ocean. The first characteristic is the potential for gas exchange between the ice and the seawater beneath [Rysgaard et al., 2007; Zhou et al., 2013; Crabeck et al., 2014], the second is the effect of partial ice cover on the gas budget inside the mixed-layer control volume. We discuss both points individually in the next two sections, starting with the mixed-layer control volume.

\subsubsection{Radon Budget Inside the Mixed-Layer Control Volume}

The theoretical basis that allows estimation of the gas flux from profiles of ${ }^{222} \mathrm{Rn}$ is based upon mass conservation of radon and radium inside a control volume bounded by the air-sea interface and the seasonal pycnocline [Broecker, 1965]. The only source is radon supported by decay of radium $\left(A_{R n}^{\text {Equil. }}\right)$. Loss of radon occurs from radioactive decay and from water-to-air gas flux $\left(F_{\mathrm{g}}\right)$,

$$
F_{g}=(\underbrace{A_{R n}^{\text {Equil. }}}_{226 \text { Ra supported }}-\underbrace{A_{R n}^{\text {Obs. }}}_{\text {Observed }}) V_{b o x}
$$

Here, $V_{\text {box }}$ is the size of the control volume, and $A_{R n}^{\text {obs. }}$, similar to $A_{R n}^{\text {Equil. }}$, is the observed radon activity per unit volume. $V_{\text {box }}$ can alternately be expressed as $V_{b o x}=S_{b o x} h_{M L}$ where $S_{b o x}$ and $h_{\mathrm{ML}}$ represent the area and height of the box bounded by the mixed-layer. In the limit of no gas flux $\left(F_{g}=0\right)$, and $A_{R n}^{\text {obs. }}$ is exactly equal to the ${ }^{226}$ Ra-supported activity $\left(A_{R n}^{\text {Equil. }}\right)$-a process known as secular equilibrium that characterizes certain radioactive decay chains with long-lived parents (e.g., $\mathrm{T}_{1 / 2}$ of ${ }^{226} \mathrm{Ra}=1599 \mathrm{yrs}$.) and short-lived daughter products (e.g., $\mathrm{T}_{1 / 2}$ of ${ }^{222} \mathrm{Rn}=3.8 \mathrm{~d}$.).

Lateral gradients are assumed to be negligible, implying that fluxes along isopycnals have no impact on the gas budget. Additionally, the method assumes that the turbulent forcing conditions and the volume of the box (i.e., $h_{\mathrm{ML}}$ ) are not varying in time. Some of these assumptions are weaker than others. Wind speed, for example, does not remain constant over the timescale of mixed-layer gas renewal (e.g., 15-30 days), and consequently a weighted average wind speed has been adopted to account for the time history of turbulent forcing in the mixed-layer [Bender et al., 2011; Cassar et al., 2011]. These assumptions are common to surface ocean geochemical budget methods, including the estimates of Net and Gross biological oxygen production [Luz et al., 1999; Kaiser et al., 2005]; with frank acknowledgement of the biases and shortcomings that result from the steady state assumption [Bender et al., 2011; Nicholson et al., 2012].

The second piece of the radon-deficit method relies upon estimation of air-sea gas flux using surface renewal theory [Liss, 1973],

$$
F_{g}=k\left(n_{R n}^{O b s}-\beta \chi_{a t m}\right) S
$$

As above, $F_{\mathrm{g}}$ is the total flux from the surface ocean box, expressed in units of atoms or decays per minute per day (DPM per day), $n_{R n}^{\text {Obs. }}$ is the aqueous concentration of radon, $\chi_{a t m}$ is the atmospheric mixing ratio of radon, $\beta$ is the Bunsen or Henry solubility, and $S$ is the surface area where radon crosses the air-sea interface. In practice, $\chi_{a t m}=0$. By combining equations ( 1 ) and (2), we obtain 


$$
\begin{gathered}
k=\frac{F_{g}}{n_{R n}^{\text {Obs. }}}=\frac{\left(A_{R n}^{\text {Equil. }}-A_{R n}^{\text {Obs. }}\right) S_{b o x} h_{M L}}{n_{R n}^{\text {Obs. }}} \\
k=\frac{F_{g}}{n_{R n}^{\text {Obs. }}}=\frac{\lambda_{222 R n}\left(A_{R n}^{\text {Equil. }}-A_{R n}^{\text {Obs. }}\right) h_{M L}}{n_{R n}^{\text {Obb. }}}=\left(\frac{n_{R n}^{\text {Equil. }}}{n_{R n}^{\text {Obs. }}}-1\right) h_{M L} \lambda_{222 R n}
\end{gathered}
$$

The final form of equation (3) is the one derived by Broecker and Peng [1971] and the same used by most subsequent studies [e.g., Smethie et al., 1985; Bender et al., 2011; Rutgers Van Der Loeff et al., 2014].

The motivation for taking the time to rederive the radon-deficit model is to draw an important distinction between the open ocean and the ice-covered ocean - that $S_{\text {box }}$ in equation (1) $\neq S$ in equation (2). Sea ice cover reduces $S$, the area of open water to some value between 0 and $S_{\text {box. }}$. Consequently, equation (3) for the sea ice zone should be expressed as

$$
k=\frac{S_{\text {box }}}{S}\left(\frac{n_{R n}^{\text {Equil. }}}{n_{R n}^{\text {Obs. }}}-1\right) h_{M L} \lambda_{222 R n}
$$

The ratio $S / S_{\text {box }}$ also represents the fraction of open water ( $f$ ), and this term can be combined with $k$ to define $k_{\text {eff }}$-the effective gas transfer velocity. The important point is that the radon-deficit (expressed as equation (3)) and other gas budget methods do not yield a value of $k$ that is comparable with open ocean $k$. Rather the two are related to each other by $f$ [Loose et al., 2014],

$$
k_{\text {eff }}=\mathrm{f} k
$$

Keeping this distinction in mind, we can compare estimates of $k$ from gradient or perturbation measurements above the air-sea interface and from gas budget or ratio methods measured in the oceanic mixedlayer. Here we present the estimates of $k_{\text {eff }}$ from equation (2) and then convert to $k$ using values derived from the time-weighted sea ice cover from the past 30 days [Rutgers Van Der Loeff et al., 2014].

2.1.2. Difficulty With Accurate Estimates of Sea Ice Cover in the Marginal Ice Zone

During the JOIS-BGOS 2013 cruise, the Canadian Coast Guard provided an ice pilot from the Canadian Ice Service (CIS). The ice pilot used CIS algorithms to estimate the ice cover and type from synthetic aperture radar (RADARSAT-2) a data source that is not publicly available. Examples of these maps can be found in Figure 2.

Subsequent to the cruise, we employed the University of Bremen SSMI data product [Grosfeld et al., 2016], which provides $6.5 \mathrm{~km}$ resolution sea ice concentration (SIC) using the SSMI passive radiometer. During the comparison of ice charts from the ice pilot and estimates of SIC from the SSMI algorithm, it became apparent that the two products showed disagreement within the marginal ice zone. Referring to Figure 2, the SSMI SIC indicates $0 \%$ ice cover along $145^{\circ} \mathrm{W}$, from the coastline to $72.5^{\circ} \mathrm{N}$, a distance of approximately $280 \mathrm{~km}$. Along the same meridian, the CIS map progresses from 20 to 80 and eventually $90+\%$ ice cover.

During the 2013 JOIS cruises, an ice camera took continuous pictures from the bridge of the ship. A comparison of these images was able to provide a qualitative validation against both data products. In general, it appears that the CIS maps are more reflective of ice observations from the bridge of the ship. At that time of year (late summer), the marginal ice zone was dominated by melt ponds. It seems likely that the melt ponds appear as open water in the SSMI radiometer, but in fact ice with melt ponds can represent nearly $100 \%$ ice cover in places. These results indicate the challenge of obtaining accurate sea ice cover estimates, at least during late summer. JOIS 2014 was a fall cruise; at that time sea ice appeared to be actively forming. Direct comparison of RADARSAT images and SSMI images indicated much better agreement, except where large fractures were underestimated. In that case, the RADARSAT images predicted a larger fraction of open water.

Here, we have used the SSMI ice cover to calculate the weighted average ice cover over the mixed-layer lifetime of ${ }^{222} \mathrm{Rn}$. We carried out the same approach using RADARSAT-2 images in 2014 and found they were relatively consistent at that time of year (late fall). The late summer stations in 2013 where the two data products differed significantly have been noted by "*" in Table 1 ; in this case, we used the estimates from the Canadian Ice Service charts. 


\section{CAGU Journal of Geophysical Research: Oceans}
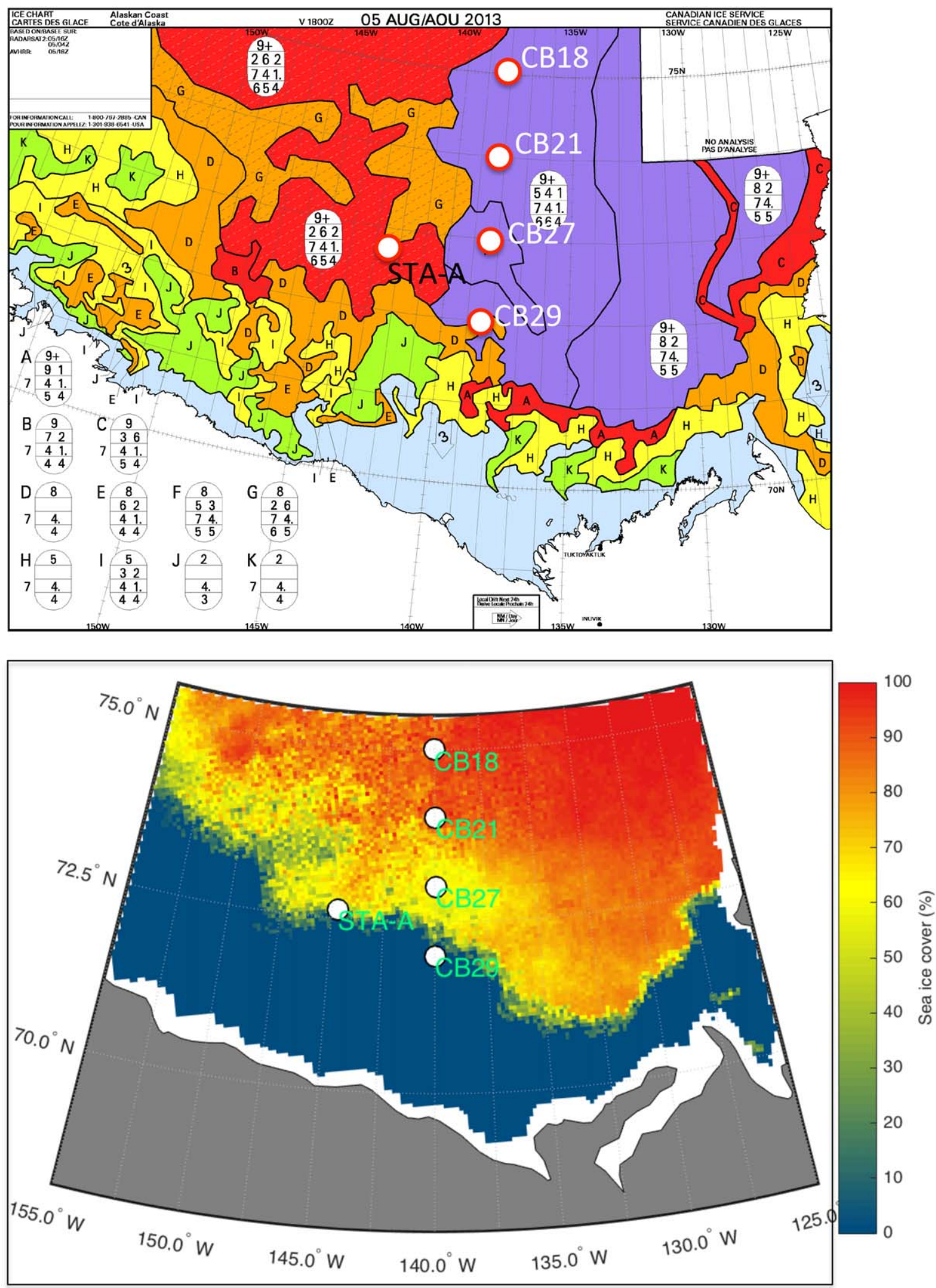

Figure 2. Comparison of Canadian Ice Service sea ice cover map (top) with the University of Bremen SSM/I data product (bottom, www.meereisportal.de). The Ice Service map is generated using RADASAT-2 imagery. (top) The ovals in the legend provide detail for each ice type (A through K). The top-most number describes the amount of ice cover on a scale of 1-10. The other numbers in the so-called "egg code" are described in detail at https://www.ec.gc.ca/glaces-ice/default.asp?lang=En\&n=D5F7EA14-1\&offset=1\&toc=hide. 
Table 1. ${ }^{222} \mathrm{Rn} /{ }^{226}$ Ra-Based Estimates of Effective Gas Transfer Velocity ( \pm Uncertainty) From 58 Profiles Taken in the Arctic Between April 1986 and November 2014

\begin{tabular}{|c|c|c|c|c|c|c|c|c|}
\hline Cruise & Station & & Lat (dd.dddd) & Lon (dd.dddd) & SIC (\%) & $\operatorname{MLD}(\mathrm{m})$ & $\mathrm{Rn} / \mathrm{Ra}$ Avg & $k_{\text {eff }}(m / d)$ \\
\hline \multirow[t]{16}{*}{ JOIS 2013} & CB01 & 05/08/2013 & 71.7721 & -131.8677 & $95.0^{*}$ & 10 & 0.88 & $0.0 \pm 0.12$ \\
\hline & CB21 & $07 / 08 / 2013$ & 74.0152 & -139.9670 & $90.0^{*}$ & 9.6 & 0.82 & $1.1 \pm 0.16$ \\
\hline & CB19 & $09 / 08 / 2013$ & 74.2969 & -143.2576 & 67.3 & 10.3 & 0.64 & $2.1 \pm 0.17$ \\
\hline & StaA & $10 / 08 / 2013$ & 72.6249 & -144.7316 & $70.0^{*}$ & 8 & 0.85 & $0.9 \pm 0.15$ \\
\hline & CB2a & $12 / 08 / 2013$ & 72.4886 & -150.0316 & $35.0^{*}$ & 11 & 0.71 & $1.3 \pm 0.18$ \\
\hline & CB6 & $13 / 08 / 2013$ & 74.6665 & -146.8517 & $65.0^{*}$ & 10 & 0.75 & $1.4 \pm 0.19$ \\
\hline & CB4 & $13 / 08 / 2013$ & 75.0095 & -149.9900 & 95.6 & 11 & 0.75 & $1.3 \pm 0.24$ \\
\hline & CB5 & $16 / 08 / 2013$ & 75.2758 & -153.3414 & 95.0 & 14 & 0.94 & $0.1 \pm 0.26$ \\
\hline & TU1 & $17 / 08 / 2013$ & 75.9900 & -160.1041 & 90.0 & 11 & 0.96 & $0.1 \pm 0.19$ \\
\hline & TU2 & $18 / 08 / 2013$ & 77.0099 & -169.9825 & 68.6 & 8 & 0.68 & $1.1 \pm 0.15$ \\
\hline & CB10 & $20 / 08 / 2013$ & 78.2986 & -153.2429 & 99.5 & 9.6 & 0.90 & $0.0 \pm 0.16$ \\
\hline & $\mathrm{CB} 11$ & $21 / 08 / 2013$ & 78.8678 & -149.9555 & 98.9 & 10.3 & 0.87 & $0.5 \pm 0.20$ \\
\hline & $\mathrm{CB} 12$ & $22 / 08 / 2013$ & 77.5158 & -147.8255 & 99.5 & 18 & 1.05 & $0.0 \pm 0.30$ \\
\hline & CB16 & $23 / 08 / 2013$ & 77.9261 & -140.1571 & 96.3 & 10 & 0.90 & $0.0 \pm 0.19$ \\
\hline & CB17 & $26 / 08 / 2013$ & 75.9868 & -139.6985 & 97.0 & 20 & 1.01 & $0.0 \pm 0.38$ \\
\hline & CB18 & $27 / 08 / 2013$ & 75.0051 & -140.0339 & 95.2 & 14 & 0.84 & $0.9 \pm 0.26$ \\
\hline \multirow[t]{18}{*}{ JOIS 2014} & CB27 & $29 / 08 / 2013$ & 73.0090 & -139.9443 & $63.0^{*}$ & 9.5 & 0.53 & $3.0 \pm 0.18$ \\
\hline & CB29 & $30 / 08 / 2013$ & 71.9978 & -139.9980 & $5.0^{*}$ & 8.5 & 0.60 & $2.7 \pm 0.16$ \\
\hline & CB-31 & $24 / 09 / 2014$ & 72.3500 & -134.0000 & 70.9 & 16 & 0.80 & $1.5 \pm 0.32$ \\
\hline & CB-27 & $26 / 09 / 2014$ & 73.0000 & -140.0000 & 91.5 & 24.5 & 0.78 & $1.8 \pm 0.46$ \\
\hline & STA-A & $28 / 09 / 2014$ & 72.6000 & -144.6970 & 1.9 & 19 & 0.71 & $3.2 \pm 0.38$ \\
\hline & CB-06 & $29 / 09 / 2014$ & 74.7000 & -146.7000 & 89.5 & 29.5 & 0.88 & $1.3 \pm 0.48$ \\
\hline & CB-07 & $01 / 10 / 2014$ & 76.0000 & -150.0000 & 90.3 & 24.5 & 0.73 & $3.7 \pm 0.49$ \\
\hline & CB-05 & $02 / 10 / 2014$ & 75.3000 & -153.3000 & 87.5 & 24.5 & 0.93 & $1.4 \pm 0.43$ \\
\hline & TU-01 & $03 / 10 / 2014$ & 76.0000 & -160.1670 & 10.3 & 17 & 0.91 & $0.0 \pm 0.33$ \\
\hline & TU-02 & $04 / 10 / 2014$ & 77.0000 & -170.0000 & 83.8 & 21.5 & 0.93 & $0.9 \pm 0.42$ \\
\hline & CB-08 & $08 / 10 / 2014$ & 77.0000 & -150.0000 & 97.1 & 22.5 & 0.82 & $0.9 \pm 0.43$ \\
\hline & CB-13 & $09 / 10 / 2014$ & 77.3000 & -143.3000 & 99.6 & 29.5 & 0.85 & $1.7 \pm 0.47$ \\
\hline & PP-07 & $11 / 10 / 2014$ & 76.5373 & -135.4338 & 98.1 & 23.5 & 0.85 & $1.7 \pm 0.39$ \\
\hline & CB-17 & $12 / 10 / 2014$ & 76.0000 & -140.0000 & 99.2 & 28.5 & 0.91 & $1.3 \pm 0.49$ \\
\hline & CB-40 & $13 / 10 / 2014$ & 74.5000 & -135.4300 & 97.2 & 25.5 & 0.84 & $1.5 \pm 0.49$ \\
\hline & CB-50 & $14 / 10 / 2014$ & 73.5000 & -134.2500 & 97.3 & 26.5 & 0.92 & $1.0 \pm 0.58$ \\
\hline & CB-28 & $15 / 10 / 2014$ & 71.0000 & -140.0000 & 8.0 & 17 & 0.88 & $1.6 \pm 0.30$ \\
\hline & CB-29 & $15 / 10 / 2014$ & 72.0000 & -140.0000 & 62.4 & 20.5 & 0.98 & $0.0 \pm 0.36$ \\
\hline \multirow[t]{18}{*}{ RL (2014) } & PS78/201-5 & $13 / 08 / 2011$ & 78.4935 & -164.2157 & 96.0 & 14 & 0.90 & $0.0 \pm 0.36$ \\
\hline & PS78/205-3 & $15 / 08 / 2011$ & 79.1478 & -155.0977 & 96.0 & 8 & 0.90 & $0.0 \pm 0.16$ \\
\hline & PS78/209-6 & $17 / 08 / 2011$ & 80.6432 & -137.2822 & 94.0 & 14.5 & 0.97 & $0.0 \pm \mathrm{NaN}$ \\
\hline & PS78/212-8 & $19 / 08 / 2011$ & 81.3582 & -130.0248 & 94.0 & 7.5 & 0.99 & $0.0 \pm 0.15$ \\
\hline & PS78/218-5 & $22 / 08 / 2011$ & 82.1645 & -128.3235 & 100.0 & 12.5 & 1.01 & $0.0 \pm 0.22$ \\
\hline & PS78/222-7 & $26 / 08 / 2011$ & 83.0272 & 58.9748 & 100.0 & 10 & 1.08 & $0.0 \pm 0.17$ \\
\hline & PS78/227-6 & 29/08/2011 & 83.3387 & 59.2895 & 98.0 & 6.5 & 0.92 & $0.0 \pm 0.13$ \\
\hline & PS78/230-4 & $31 / 08 / 2011$ & 84.0738 & 59.4440 & 98.0 & 2 & 1.03 & $0.0 \pm 0.03$ \\
\hline & PS78/235-5 & $02 / 09 / 2011$ & 84.3785 & 59.6825 & 100.0 & 14 & 1.09 & $0.0 \pm 0.26$ \\
\hline & PS78/239-4 & 05/09/2011 & 84.7950 & 119.1825 & 99.0 & 11.5 & 0.99 & $0.0 \pm 0.22$ \\
\hline & PS78/245-3 & 08/09/2011 & 85.0617 & 120.7967 & 99.0 & 8 & 0.92 & $0.0 \pm 0.17$ \\
\hline & PS78/250-4 & $11 / 09 / 2011$ & 85.5195 & 121.3322 & 96.0 & 20.5 & 1.00 & $0.0 \pm 0.46$ \\
\hline & PS78/257-3 & $13 / 09 / 2011$ & 86.3287 & 124.1093 & 69.0 & 20.5 & 0.96 & $0.0 \pm 0.43$ \\
\hline & PS78/271-3 & $19 / 09 / 2011$ & 86.8615 & 124.8795 & 56.0 & 13.5 & 1.00 & $0.0 \pm 0.33$ \\
\hline & PS78/273-3 & $19 / 09 / 2011$ & 86.9822 & 125.7842 & 0.0 & 6 & 0.79 & $0.6 \pm 0.16$ \\
\hline & PS78/276-3 & $20 / 09 / 2011$ & 88.0225 & 130.4107 & 0.0 & 20.5 & 0.72 & $2.9 \pm 0.45$ \\
\hline & PS78/280-3 & $21 / 09 / 2011$ & 88.7410 & 139.8800 & 0.0 & 17.5 & 0.61 & $3.8 \pm 0.45$ \\
\hline & PS78/285-3 & $22 / 09 / 2011$ & 89.9653 & 166.4087 & 0.0 & 13.5 & 0.58 & $4.3 \pm 0.38$ \\
\hline \multirow[t]{6}{*}{ FT91 } & Ice Station 2 & N/A & 80.2551 & 29.9122 & 69.7 & 15 & $\mathrm{~N} / \mathrm{A}$ & $4.3 \pm N / A$ \\
\hline & Ice Station 3 & $\mathrm{~N} / \mathrm{A}$ & 79.6333 & 30.3572 & 71.0 & 17.5 & $\mathrm{~N} / \mathrm{A}$ & $2.5 \pm N / A$ \\
\hline & 43 & $\mathrm{~N} / \mathrm{A}$ & 74.7876 & 30.5512 & 1.3 & 110 & $\mathrm{~N} / \mathrm{A}$ & $1.4 \pm \mathrm{N} / \mathrm{A}$ \\
\hline & 52 & $\mathrm{~N} / \mathrm{A}$ & 73.9312 & 26.6942 & 0.4 & 63 & N/A & $3.5 \pm N / A$ \\
\hline & $\mathrm{H} 1$ & $\mathrm{~N} / \mathrm{A}$ & 74.2965 & 34.2506 & 3.5 & $\mathrm{~N} / \mathrm{A}$ & $\mathrm{N} / \mathrm{A}$ & $0.0 \pm N / A$ \\
\hline & 37 & $\mathrm{~N} / \mathrm{A}$ & 73.8037 & 32.9294 & 0.2 & $\mathrm{~N} / \mathrm{A}$ & $\mathrm{N} / \mathrm{A}$ & $0.0 \pm N / A$ \\
\hline
\end{tabular}

aThe cruise marked RL (2014) refers to the profiles and study published by Rutgers Van Der Loeff et al. [2014]. Cruise marked as FT91 were taken from the 1986 and 1988 cruises of Fanning and Torres [1991]. SIC values that are noted with an " indicate the sea ice cover was determined from Canadian Ice Service charts, because the SSMI satellite ice cover appeared affected by melt ponds.

2.1.3. ${ }^{222} \mathrm{Rn} /{ }^{226} \mathrm{Ra}$ Inside Sea Ice

Sea ice can both store and transport dissolved gases. This is particularly true for biogenic gases such as $\mathrm{O}_{2}$, $\mathrm{CO}_{2}$, DMS, and $\mathrm{CH}_{4}$ [Delille et al., 2007; Rysgaard et al., 2009], but also true for any inert gas that is present in 
the ocean or the atmosphere [Zhou et al., 2013]. During freezing, gases, and ions in seawater are excluded from the ice crystal structure and become concentrated with other solutes inside brine pockets that aggregate along ice crystal grain boundaries [Killawee et al., 1998; Notz and Worster, 2009]. Radium is an alkali earth metal, similar to calcium and strontium. In seawater it exists as a doubly charged cation, so it should behave like $\mathrm{Na}$ and $\mathrm{Ca}$ during the formation and desalination of sea ice. First year sea ice typically has a bulk salinity between 5 and 12 psu [Petrich and Eicken, 2010], or approximately 30\% of the salinity of seawater. Assuming that ${ }^{226} \mathrm{Ra}$ accumulates in sea ice at the same rate as salt (which may be an underestimate if significant organic matter is present), Radium activity within sea ice should be $\sim 3$ Decays Per Minute per $100 \mathrm{~L}(\mathrm{DPM} / 100 \mathrm{~L})$ of melted sea ice.

If the ice were entirely impermeable to air-sea gas flux, the activity of radon would be in equilibrium with radium at $\sim 3 \mathrm{DPM} / 100 \mathrm{~L}$. However, air-ice gas flux is known to occur. If we use an estimate of the air-ice transfer velocity across a $2 \mathrm{~m}$ thick ice cover $\left(k_{\text {ice }}=8.6 \times 10^{-4} \mathrm{md}^{-1}\right)$ from Crabeck et al. [2014], the flux of radon at the air-sea interface would be $F_{R n}=8.6 \times 10^{-4 *}\left(30 \mathrm{DPM} \mathrm{m}^{-3}\right)=0.026 \mathrm{DPM} \mathrm{m}^{-2} \mathrm{~d}^{-1}$. In comparison, the same $2 \mathrm{~m}$ thick ice cover would have a steady state inventory of $60 \mathrm{DPM} \mathrm{m} \mathrm{m}^{-2}$. This loss term is effectively negligible compared to the continual replacement and decay of radon from radium activity, and therefore ${ }^{222} \mathrm{Rn}$ and ${ }^{226} \mathrm{Ra}$ should be in secular equilibrium within sea ice.

To verify this assumption, two ice core samples were collected in 2014. They were placed inside "Keybler" vessels (see section 2.2 for description of Keybler) and allowed to melt in a helium atmosphere. Altogether 18 and $19 \mathrm{~L}$ of ice water equivalent were collected and analyzed. The resulting radon activities were 2.7 and 3.8 DPM/100 L. Bulk salinity in the two ice cores were 9.1 and $11.3 \mathrm{~g} \mathrm{~kg}^{-1}$, compared to surface ocean salinity of $28.6 \mathrm{~g} \mathrm{~kg}^{-1}$, or approximately 31 and $39 \%$ of surface ocean salinity. In the second core, we believe we inadvertently collected seawater slush from the core hole. In comparison to the mean mixed-layer ${ }^{226} \mathrm{Ra}$ of $11 \mathrm{DPM} / 100 \mathrm{~L}$ at this station, 2.7 and 3.8 DPM/100 L are $25 \%$ and $35 \%$ of water-column radium activity, indicating an approximate correspondence with the bulk salinity remaining in the ice, and suggesting that the ice ${ }^{222} \mathrm{Rn}$ and ${ }^{226} \mathrm{Ra}$ are in secular equilibrium within the ice.

How does sea ice melt affect the radon and radium budget of the surface ocean? If we suppose a $2 \mathrm{~m}$ thick ice cover overlying a $10 \mathrm{~m}$ mixed-layer, we can estimate the change in the gas ratio that results from the sea ice melt. The outcome depends in part on the ${ }^{222} \mathrm{Rn} /{ }^{226} \mathrm{Ra}$ ratio. If the ratio is less than one, say ${ }^{222} \mathrm{Rn} /{ }^{226} \mathrm{Ra}=7 / 10$, then the water-column activity of radon $\left(A_{R n}\right)$ and radium $\left(A_{R a}\right)$ after sea ice melt is

$$
\begin{gathered}
A=\frac{Z_{\text {ice }}}{Z_{\text {ice }}+Z_{M L}} A^{\text {ice }}+\frac{Z_{M L}}{Z_{\text {ice }}+Z_{M L}} A^{M L} \\
A_{R n}=\frac{2}{12} 3+\frac{10}{12} 7=6.33 \\
A_{R a}=\frac{2}{12} 3+\frac{10}{12} 10=8.83
\end{gathered}
$$

This causes the activity ratio to move from ${ }^{222} \mathrm{Rn} /{ }^{226} \mathrm{Ra}=0.7$ to ${ }^{222} \mathrm{Rn} /{ }^{226} \mathrm{Ra}=0.75$. In other words, the melt of sea ice can lead to a mixed-layer gas ratio that appears less depleted. If ${ }^{222} \mathrm{Rn} /{ }^{226} \mathrm{Ra}=1$ in the water column before ice melt, then both radon and radium are equally affected by ice melt and the activity ratio remains as 1 . In either case, the impact of sea ice melt on the activity ratio in the mixed-layer will be smallusually less than $10 \%$ over the entire melt season, which is significantly longer than the e-folding time of radon in the mixed-layer, e.g., 5.5 days.

The measurements and calculations therefore imply that ice melt as well as ice formation (and brine rejection) will move the mixed-layer activity ratio closer to 1 . The timing and magnitude of sea ice formation/ melt are difficult to pinpoint; however, we can conclude that both processes will result in a value of $k_{\text {eff }}$ that appears smaller than the actual gas transfer kinetics. This is helpful in considering how to weigh radonderived profiles of $k_{\text {eff }}$ from the sea ice zone.

\subsection{Sampling and Analysis of ${ }^{222} \mathrm{Rn}$ and ${ }^{226} \mathrm{Ra}$ During JOIS 2013 and 2014}

Samples for ${ }^{222} \mathrm{Rn}$ and ${ }^{226} \mathrm{Ra}$ analysis were collected aboard the Canadian icebreaker CCGS Louis S. StLaurent (LSSL) in the Canada Basin from 1 August to 2 September 2013 (late Summer), and from 18 September to 14 October 2014 (early Fall) as part of the annual combined Fisheries and Oceans Canada Joint Ocean 
Ice Studies (JOIS) and Woods Hole Oceanographic Institution's Beaufort Gyre Observing System (BGOS) expeditions (Figure 1).

The sampling and extraction of ${ }^{222} \mathrm{Rn}$ follows the approach of Mathieu et al. [1988]. Water samples for ${ }^{222} \mathrm{Rn}$ abundance were collected in $30 \mathrm{~L}$ gas-tight PVC bubbler vessels or "Keyblers" for subsequent degassing. Discrete samples were collected in vertical profile fashion at 6-8 depths within $70 \mathrm{~m}$ of the ocean surface layer. During 2013, samples were collected via one of two methods-by submersible pump or from the foredeck rosette. When samples were collected by submersible pump, $26 \mathrm{~L}$ were collected in each Keybler bottle. When collected from the Niskin bottles, two $10 \mathrm{~L}$ Niskins were closed at one depth and drained into a single Keybler. Niskin sampling usually resulted in 18-19 L sample, as some water was left for sampling for salts. Prior to collection of water samples, the $30 \mathrm{~L}$ Keybler bottles were evacuated to a vacuum of at least -25 in $\mathrm{Hg}$ gauge pressure, to minimize contamination with air and to facilitate filling the bottles by suction. Water was inlet to the Keybler through a fitting with stopcock at the base of the sample container.

It is common for the LSSL to use compressed air bubblers to push ice away from the sides of the ship when on station. The bubbling was a cause for concern because of the potential to enhance radon loss from the surface layer. To avoid this artifact during JOIS 2013, the ship would drift on to a station prior to deploying the submersible pump to take water at two depths above $10 \mathrm{~m}$ (the draft of the ship), and prior to using the bubblers to maintain a station location. In addition, CTD profiles were taken using a freefalling Underway CTD attached to a handheld line. These two methods were used to sample the undisturbed surface layer. Subsequently, water was sampled from the Niskin CTD rosette from depths between 10 and $70 \mathrm{~m}$. At four stations, the entire set of discrete samples was collected using the submersible pump. These stations were CB-17, CB-18, CB-27, and CB-29. During JOIS 2014, cold temperatures prohibited foredeck Niskin sampling, so the entire profile of radon and radium samples was collected using submersible pump from a position near the stern of the boat. Sampling aerated water was less problematic being away from the bow of the boat, where the bubblers are located. On those occasions when a mass of aerated water moved past the stern, the Keybler intake was shut off until aerated water had drifted away from the side of the ship.

The 3.8 day half-life of ${ }^{222} \mathrm{Rn}$ requires that water samples be analyzed for radon aboard the ship. Once collected, the 24-27 L of water in the Keybler were connected to the extraction board. Helium fills the Keybler to neutral gauge pressure and a diaphragm pump is used to bubble the helium through the Keybler, stripping the radon gas from the water and transporting it through a charcoal column bathed in a slurry of dry ice and 1-propanol $-78^{\circ} \mathrm{C}$. Each extraction lasted 90-120 min. Subsequently, the charcoal traps were heated to $450^{\circ} \mathrm{C}$ and purged with helium to flush the trapped radon into a cell for counting. The cell is coated with zinc sulfide, which gives off three photons for every atom of radon that decays within the cell. Photon emissions are counted on a photon counter. To improve statistical uncertainty, each cell was counted for a period long enough to accumulate at least 1000 counts. Cells are recounted on different counters to help eliminate any bias in the efficiency or other matrix effects between cells and counters. Typically, 1000 counts accumulated on a minimum of four different counters.

After gas extraction, the water in the Keybler was gravity drained through a $\mathrm{MnO}_{2}$ impregnated acrylic fiber cartridge to sorb dissolved ${ }^{226} \mathrm{Ra}$ from the sea water. These filters were stored for analysis of ${ }^{226} \mathrm{Ra}$ abundance by gamma spectroscopy in the laboratory at URI-GSO.

\subsubsection{Extraction Efficiency, Reproducibility, and Blank Correction}

The fidelity of the extraction system was verified using NIST $4967{ }^{226}$ Ra standard solution. Activities ranging from 0.64 to $32.4 \mathrm{dpm}$ were measured on each extraction board. The extraction efficiency was $97 \%$ or greater at all activities along the calibration curve. At sea, the extraction efficiency and length of bubbling time was confirmed by repeated extraction of the same water sample. By this method, a 90 min extraction time was used to ensure all ${ }^{222} \mathrm{Rn}$ was degassed from each $24-27 \mathrm{~L}$ water sample.

The ${ }^{222} \mathrm{Rn}$ blank was determined by successive in-growth experiments for each charcoal extraction column. The sealed charcoal columns were allowed to rest for a period of 12-450 $\mathrm{h}$ and were then connected to the extraction boards and extracted using the normal 90 min extraction procedure. The in-growth experiments showed that each ${ }^{222} \mathrm{Rn}$ background asymptotes to a constant value within $450 \mathrm{~h}$. Unique blank correction curves for each extraction column were determined in order to account for the slight differences in charcoal 
mass found within each extraction column. All other sources of ${ }^{222} \mathrm{Rn}$ in the extraction board, including ascarite and drierite for removing water vapor and carbon dioxide, were found to have a negligible contribution to the ${ }^{222} \mathrm{Rn}$ blank.

To test the reproducibility of radon samples collected by the rosette, all 12 bottles were tripped at the same depth and extractions were carried out on a total of six Keyblers filled from these 12 bottles. Assuming that internal wave activity can be ruled out over the $12 \mathrm{~min}$ that it takes to trip all of the bottles, we observed a $1-\sigma$ coefficient of variation $(\sigma / \mu) \times 100$ of $2.2 \%$ on the value of ${ }^{222} \mathrm{Rn}$ and $5.6 \%$ on ${ }^{226}$ Ra values.

\section{Results and Discussion}

\subsection{Previous Estimates of Radon-Deficit in the Arctic Ocean}

Prior to 2014, there was only one published estimate of air-sea gas transfer velocity in the Arctic [Fanning and Torres, 1991]. This study, referred to hereafter as FT91, carried out measurements during two expeditions in April 1986 (early spring) and September 1988 (late summer). FT91 has been formative, because it was the first to observe both ${ }^{222} \mathrm{Rn} /{ }^{226} \mathrm{Ra}$ secular equilibrium at the ocean surface beneath $100 \%$ ice cover, and the first to reveal significant ${ }^{222} \mathrm{Rn}$ deficits beneath partial ice cover. The estimates of $k_{\text {eff, }}$ normalized to a Sc number of 660 from the four late winter stations with greater than $90 \%$ ice cover are $k_{\text {eff }}=1.4,3.5,0$, and $0 \mathrm{~m} \mathrm{~d}^{-1}$, respectively (Table 1). The values of $k_{\text {eff }}$ estimated at two of the late summer stations with less than $70 \%$ ice cover were presented as a range: $k_{\text {eff }}=2.5$ to $6.1 \mathrm{~m} \mathrm{~d}^{-1}$ and 1.2 to $1.8 \mathrm{~m} \mathrm{~d}^{-1}$. A third late summer station was sampled; however, FT91 describe that possible contact with sediments caused an anomalous bulge in the radon profile.

We attempted to verify the estimates of ice cover using the SSMI NASA Team algorithm, which was available for 1986 and 1988. The SIC estimates from the late summer station were 70, 71, and 24\% ice cover-in good agreement with the estimates reported by FT91. However, the early spring stations had SIC ranging from 0 to $3 \%$ ice cover, according to the SSMI data product. In contrast, FT91 report that all four stations were north of the ice edge in thin ice. This may likely be a difficulty with the satellite-derived estimate at the ice edge, where ice cover is particularly variable.

The next estimates $k$ in the Arctic by radon-deficit did not occur until August-September 2011 [Rutgers Van Der Loeff et al., 2014], after the Arctic had moved into a stage of advancing summer sea ice retreat. This study has provided 18 individual estimates of $k_{\text {eff }}$ from the Central Arctic and Eurasian Basin. Here, we have recomputed the values of $k_{\text {eff }}$ from the profiles made by Rutgers Van Der Loeff et al., [2014] - hereafter RL14-in order to utilize the same criteria that we applied to the JOIS 2013 and 2014 radon deficits.

The 34 estimates of $k_{\text {eff }}$ from JOIS 2013 and 2014, as well as the estimates from RL14 and FT91 can be found in Table 1. The profiles of radon and radium can be found at the Arctic Data Center (https://arcticdata.io/ metacat/d1/mn/v2/object/arctic-data.9553.1).

\subsection{Uncertainty Bounds on the ${ }^{222} \mathrm{Rn} /{ }^{222} \mathrm{Ra}$ Activity Ratio and $\boldsymbol{k}_{\text {eff }}$}

We determined the analytical uncertainty for the radon and radium estimates with two approaches: by repeated counting $(\mathrm{N}=4)$ of the same sample on different scintillation counters and by extraction of water from the same depth using all eight Keyblers and all four extraction boards. As described in section 2.2.1, extraction of the same water parcel yielded a $2.2 \%$ uncertainty on the value of ${ }^{222} \mathrm{Rn}$ and a $5.6 \%$ uncertainty on ${ }^{226} \mathrm{Ra}$ values. The repeated counts yielded an average standard error over both 2013 and 2014 cruises of $\mathrm{SE}_{\mathrm{Rn}}=0.64 \mathrm{DPM} / 100 \mathrm{~L}$ and $\mathrm{SE}_{\mathrm{Ra}}=0.70 \mathrm{DPM} / 100 \mathrm{~L}$, which are, respectively, $6.4 \%$ and $6.7 \%$ uncertainty on the radon and radium measurements.

In addition to the uncertainty on the activity of radon and radium, we must consider the uncertainty in the steady state assumptions, particularly those caused by shoaling or deepening of the mixed-layer. Bender et al. [2011] conducted a thorough analysis of this uncertainty and its effect on the gas transfer velocity; that variations in the mixed-layer introduce a systematic bias toward smaller value of $k$, but they treat this bias as part of the random error and estimate 10\% uncertainty in the radon-deficit from changes in the mixed-layer depth. Here, we utilize a Taylor approximation to propagate the error in $A_{R n}, A_{R a}$ and $z_{M L}$ through equation (4) to determine the uncertainty on $k_{\text {eff. }}$. 


$$
\operatorname{Var}\left[k_{\mathrm{eff}}\right]=\left(\frac{\partial k_{\mathrm{eff}}}{\partial z_{M L}}\right)^{2} \operatorname{Var}\left[z_{M L}\right]+\left(\frac{\partial k_{\mathrm{eff}}}{\partial A_{R n}}\right)^{2} \operatorname{Var}\left[A_{R n}\right]+\left(\frac{\partial k_{\mathrm{eff}}}{\partial A_{R a}}\right)^{2} \operatorname{Var}\left[A_{R a}\right]
$$

The uncertainty in $k_{\text {eff }}$ from these sources introduces an error into the estimate of $k$ from $k_{\text {eff }}$ that averages $0.32 \mathrm{~m} \mathrm{~d}^{-1}$, or approximately $25 \%$ of the full-scale average of $k_{\text {eff }}$. This is less than reported by Bender et al. [2011] and references therein, which arrive at 35\% error overall. The uncertainty in radon and radium activity in this study is nearly identical to the $0.5 \mathrm{DPM} / 100 \mathrm{~L}$ that Bender et al. [2011] report for the GEOSECS data set; we also attribute the decrease in the uncertainty to the likelihood that the mixed layers in the Arctic during 2013 and 2014 were significantly shallower than the mixed layers during GEOSECS and during previous studies in the Arctic [Peng et al., 1979; Fanning and Torres, 1991]. Equation (7) was also used to compute the uncertainties in the ${ }^{222} \mathrm{Rn} /{ }^{226} \mathrm{Ra}$ activity ratio and gas transfer velocities that are found in Table 1.

Previous studies have used different approaches to estimate $k$ from the observed radon-deficit (equation (4)). These include numerical integration of the observed deficit compared to secular equilibrium by trapezoidal method [Smethie et al., 1985; Fanning and Torres, 1991], and computation of the average activity ratio in the mixed-layer [Peng et al., 1979; Rutgers Van Der Loeff et al., 2014]. Most authors have defined the deficit region as being bounded between the water surface and the base of the mixed-layer; however Fanning and Torres [1991] observed deficits below the mixed-layer and included those deficits down to the region of secular equilibrium in their calculation.

We computed $k_{\text {eff }}$ using both approaches-numerical integration and by the average activity ratio in the mixed-layer. Both methods applied to individual profiles varied by as much as $0.8 \mathrm{~m} \mathrm{~d}^{-1}$, and on average by $0.2 \mathrm{~m} \mathrm{~d}^{-1}$. Overall, the average of the activity ratio produced values $k_{\text {eff }}$ that were $0.1 \mathrm{~m} \mathrm{~d}^{-1}$ greater than the trapezoidal method. As these values are all within the estimated analytical uncertainty of $0.32 \mathrm{~m} \mathrm{~d}^{-1}$, we consider the estimates by both methods to be comparable. In this study, we report values of $k_{\text {eff }}$ using the trapezoidal integration. The activity ratio used in equation (4) represents a trapezoidal integration of the radon profile above the mixed-layer depth, subtracted from a trapezoidal integration of the radium profile, also bounded by the base of the mixed-layer. Consistent with FT91 and RL14, we observed radon deficits beneath the mixed-layer (e.g., Figures $3 c$ and $3 f$ ). However, we attribute those deficits to analytical uncertainty or to more complex lateral ventilation processes that do not necessarily fit the 1-D approximations of the radon-deficit method.

\subsection{Weighting Wind Speed and Sea Ice Cover for the Duration of Mixed-Layer Tracer Memory}

Based upon equation (5), $k$ can be computed from $k_{\text {eff }}$ using an estimate of the fraction of open water ( $f$ ). As with wind speed, the radon-deficit will have a "tracer memory" of the ambient ocean surface layer conditions over the past 15-30 days [Bender et al., 2011], including a memory of the variations in $f$ over this period. To account for the tracer memory effect, a weighting method has been introduced that accounts for wind forcing events throughout the period of memory and assigning smaller weight to events that are further back in time [Reuer et al., 2007] and for the radioactive decay of radon [Bender et al., 2011; Rutgers Van Der Loeff et al., 2014]. The weighting method has been described in detail in Bender et al. [2011]. For determining $f$ we use,

$$
\mathrm{f}=\frac{\sum_{i=1}^{30} \mathrm{f}_{i} w_{i-1}\left(1-\left(\frac{A_{\text {box }}}{S}\right)_{i-1} \frac{h_{M L}}{k}\right) e^{-\lambda t}}{\sum_{i=1}^{30} W_{i-1}\left(1-\left(\frac{A_{b o x}}{S}\right)_{i-1} \frac{h_{M L}}{k}\right) e^{-\lambda t}}
$$

where $w_{i-1}$ is the weighting from the previous time interval, $\left(\frac{A_{b o x}}{S}\right)_{i-1}$ emerges from equation (4) and represents the reciprocal of open water fraction: 1/f. The larger the open water fraction, the faster the gas exchange and therefore, the greater the weight applied to that value of $\mathrm{f}$. The value 30 represents the 30 day tracer memory, and we use daily values of sea ice cover from the SSMI microwave radiometer, processed to yield $6.25 \mathrm{~km}$ resolution [Spreen et al., 2008]. A similar approach is applied to weighting the 30 day wind speed. The term $\lambda=0.181 \mathrm{~d}^{-1}$ is the decay constant for radon. Further detail can be found in the appendix of Bender et al. [2011].

The mean mixed-layer activity ratio $\left({ }^{222} \mathrm{Rn} /{ }^{226} \mathrm{Ra}\right)$ during JOIS 2013 was $0.82(\mathrm{~N}=18$ stations) and during JOIS 2014 was 0.86 ( $\mathrm{N}=16$ stations). Two of the 34 stations exhibited mixed-layer values of ${ }^{222} \mathrm{Rn} /{ }^{226} \mathrm{Ra}$ 

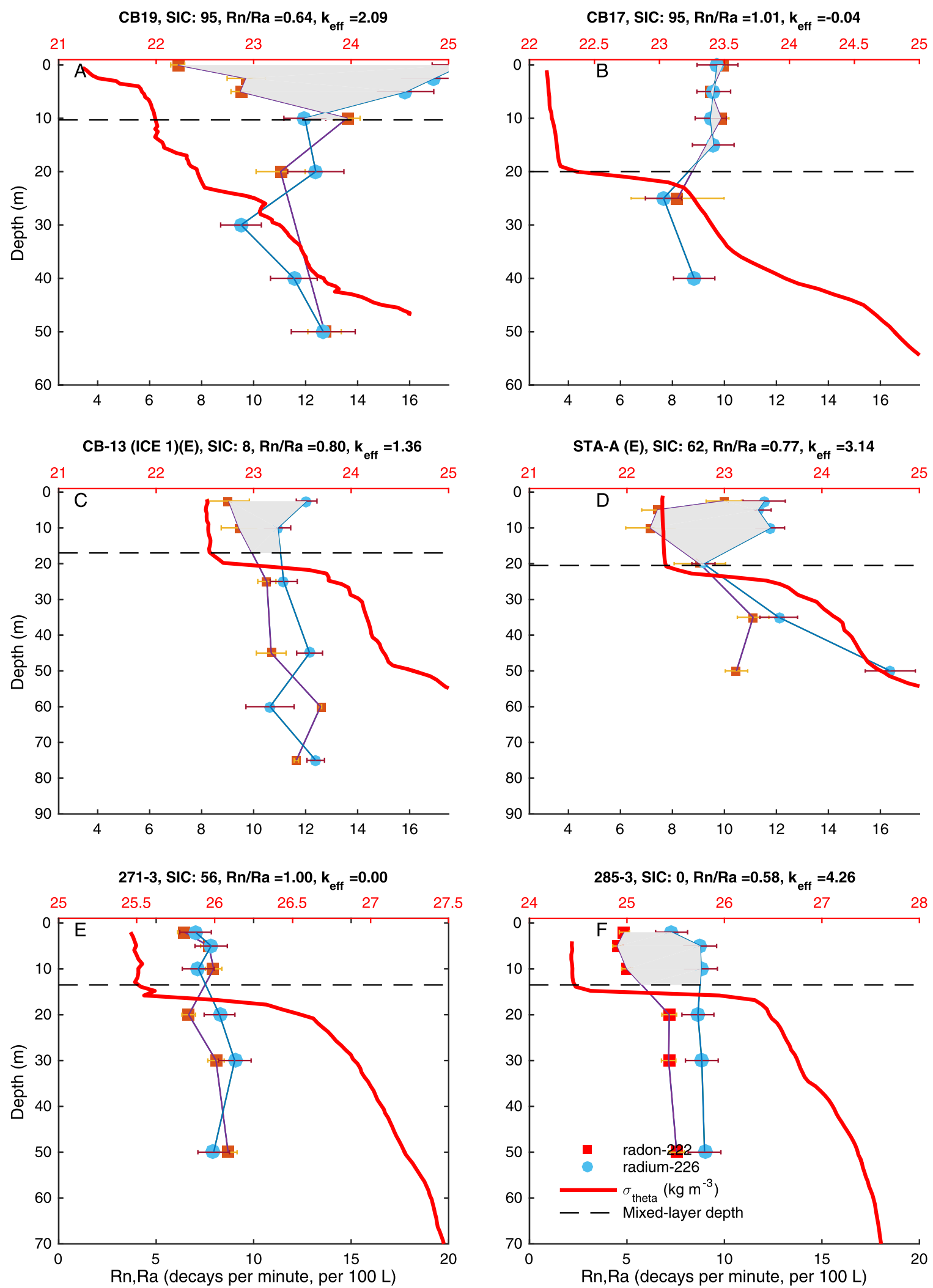

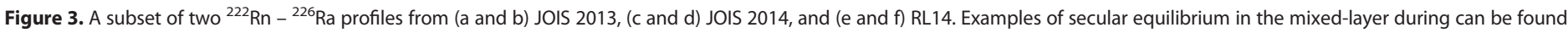
in Figures $3 \mathrm{~b}$ and $3 \mathrm{e}$. Despite only $56 \%$ ice cover, Figure 3 e shows no evidence of gas exchange, while Figure $3 \mathrm{a}$ indicates a significant radon-deficit, despite $95 \%$ ice cover. Plots of all profiles from JOIS 2013, 2014, and RL14 can be found in the supporting information. 
greater than 1.0, and 12 of the 34 stations had mixed-layer ${ }^{222} \mathrm{Rn} /{ }^{226} \mathrm{Ra}>0.9$. As with the studies of FT91 and RL14, we observed secular equilibrium right up to the ice-water interface, indicating that under the right conditions the gas transfer velocity becomes effectively zero, within analytical uncertainty, or $0.00 \pm 0.32 \mathrm{~m} \mathrm{~d}^{-1}$.

For the purposes of estimating bulk gas transfer statistics, we only computed a transfer velocity if values of $A_{R a}$ and $A_{R n}$ in the mixed-layer were distinguishable within analytical uncertainty (Figure 3). If none of the samples in the mixed-layer are distinguishable within analytical uncertainty, the effective transfer velocity is reported as zero. This is a different approach than that taken by RL14 who reported negative transfer velocities when the activity ratio exceeded one. Here, we are interested in recording the instances when the transfer velocity was effectively zero for purposes of computing the mean of $k$ and $k_{\text {eff }}$ during different ice cover regimes. We have applied the same criteria to the ${ }^{222} \mathrm{Rn} /{ }^{226} \mathrm{Ra}$ profiles from $\mathrm{RL} 14$, in order to include their results in the statistical analysis. We were not able to obtain the radon and radium profiles from FT91, so these have not been included in the statistical analysis, but their derived values of $k_{\text {eff }}$ can be found in Table 1 and Figure 4.

The average value of $k_{\text {eff }}$ during JOIS 2013, the late summer cruise, was $0.91 \mathrm{~m} \mathrm{~d}^{-1}$ with a weighted open water fraction of $f=0.21$; using equation (5) this yields a mean value of $k=4.3 \mathrm{~m} \mathrm{~d}^{-1}$. Five of the 18 radondeficit profiles were so close to secular equilibrium that the transfer velocity was indistinguishable from zero (see green circles in Figure 4). The average shipboard wind speed from 1 July (30 days before cruise) to 30 August was $5.4 \mathrm{~m} \mathrm{~s}^{-1}$. Using the Wanninkhof [2014] wind speed parameterization $\left(k_{\mathrm{ws}}=0.062 U^{2}\right)$ predicts a mean transfer velocity of $k_{\mathrm{ws}}=1.8 \mathrm{~m} \mathrm{~d}^{-1}$. We use this value of $k_{\mathrm{ws}}$ and $\mathrm{f}$ to estimate $k_{\text {eff }}$ predicted from wind speed: $k_{\text {eff,ws }}=f k_{\mathrm{ws}}$ for 2013 are plotted as a black line in Figure 4.

During JOIS 2014, the early summer cruise, the mean of $k_{\text {eff }}$ was $1.4 \mathrm{~m} \mathrm{~d}^{-1}$ with an average opening of $\mathrm{f}=0.26$. This translates to an average transfer velocity $(k)$ of $5.3 \mathrm{~m} \mathrm{~d}^{-1}$. Three of the 16 radon-deficit profiles were close to secular equilibrium in the mixed-layer and as a result yield $k_{\text {eff }}=0$. The average wind speed from 24 August (30 days before the first radon measurement) to 15 October was $7.6 \mathrm{~m} \mathrm{~s}^{-1}$, and the Wanninkhof [2014] relationship predicts $k=3.5 \mathrm{~m} \mathrm{~d}^{-1}$. Collectively, the greater wind speed during JOIS 2014 coincides with a larger average value of $k$, compared to JOIS 2013.
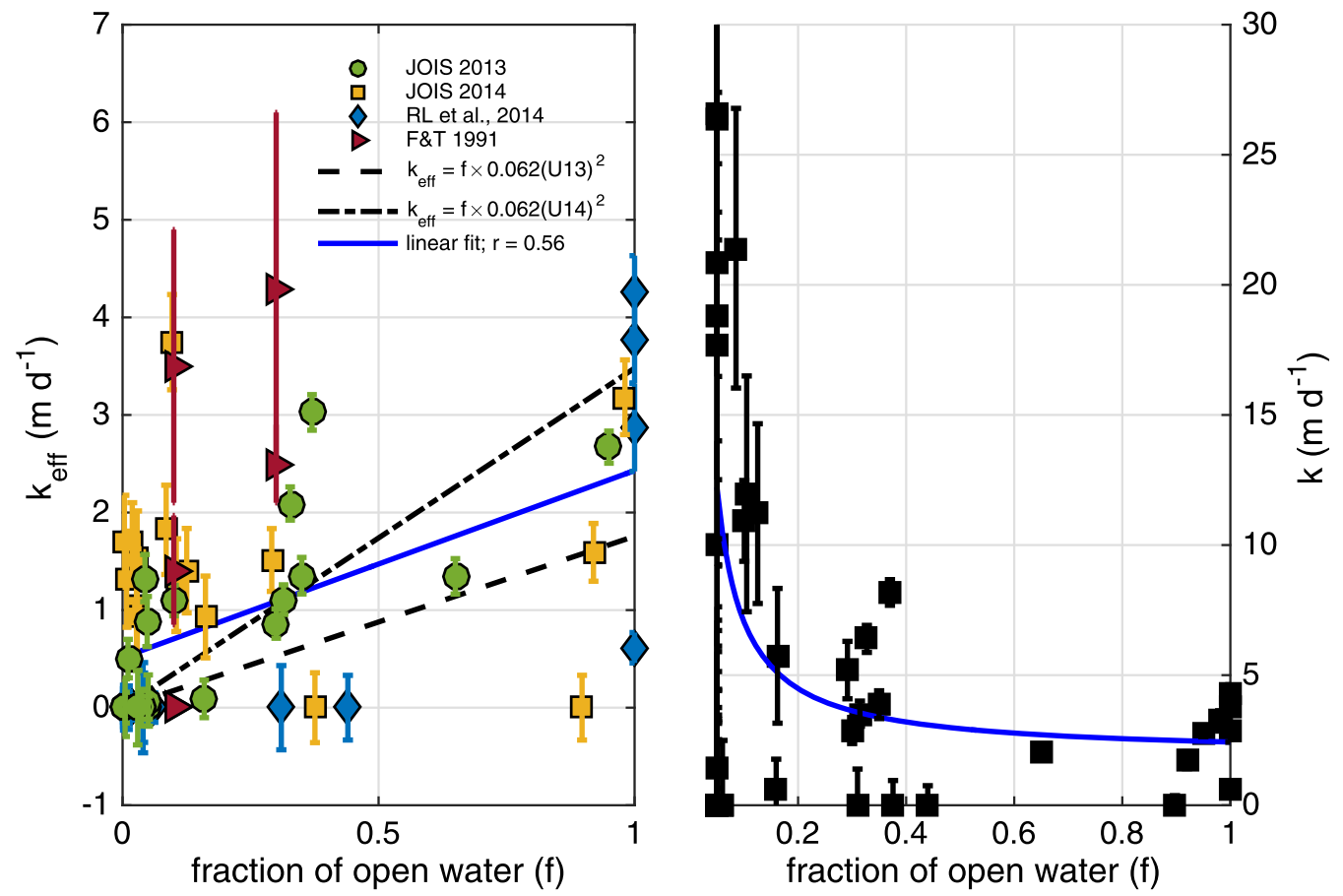

Figure 4. (left) The effective gas transfer velocity $\left(k_{\text {eff }}\right)$ plotted versus radon-weighted fraction of open water $(f)$ using the weighting method of Bender et al. [2011]. (right) The area-independent transfer velocity, $k$, computed from $k_{\text {eff }}$ as $k=k_{\text {eff }} / f$. The blue curve is the same linear fit as the left plot, but also converted to $k$. 
Table 2. Chi-Squared Goodness of Fit Tests for the Five Gas Exchange Parameterizations Used by [Bender et al., 2011] to Observe Whether Wind Speed Is an Adequate Predictor of Radon-Deficit Estimates of Transfer Velocity in the Sea Ice Zone ${ }^{a}$

\begin{tabular}{lrccc} 
& A: $\chi^{2}$ & B: $\chi^{2}$ & C: $\chi^{2}$ & D: $\chi^{2}$ \\
\hline Wanninkhof and McGillis [1999] & 1876.2 & 827.1 & 821.1 & 1.01 \\
Nightingale et al. [2000] & 898.8 & 333.1 & 327.1 & 0.90 \\
Ho et al. [2006] & 1041.7 & 381.6 & 375.6 & 0.83 \\
Sweeney et al. [2007] & 784.6 & 290.5 & 284.5 & 0.99 \\
Wanninkhof [2014] & 923.2 & 342.2 & 336.2 & 0.89 \\
$\chi_{\text {cr }}^{2}$ & 67.5 & 38.9 & 30.0 & 11.0 \\
DOF & 51 & 26 & 20 & 5
\end{tabular}

${ }^{\text {a }}$ Four different tests were attempted: A—using all 52 radon-deficit profiles, B-removing profiles that showed secular equilibrium in the mixed-layer $\left(k_{\text {eff }}=0\right), C$-additionally removing profiles where $f<0.05$, and D-analyzing only profiles with $\mathrm{f}>0.95$ or in nearly $100 \%$ open water

Applying the criteria described above in this section to the profiles of RL14, yields a mean $k_{\text {eff }}=0.64 \mathrm{~m} \mathrm{~d}^{-1}$ with an open water fraction of $f=0.28$. Fourteen of the 18 profiles indicated ${ }^{222} \mathrm{Rn}$ that met or exceeded secular equilibrium indistinguishable from zero. The average shipboard wind speed from Table 2 of RL14 was $6.8 \mathrm{~m} \mathrm{~s}^{-1}$.

\subsection{Covariation Between Gas Transfer Velocity and Ice Cover}

The 34 radon-deficit profiles from the JOIS cruises and the 18 profiles from RL14 represent 52 unique measurements of $k_{\text {eff }}$ in the Arctic, spanning a range of open water fraction from $f=0$ to 1 . However, the samples are not evenly distributed over the range of $f ; 29$ of the 52 samples were measured at $f<0.1$ and another 7 are found at $f>0.9$. In other words, $70 \%$ of the samples are found at the two extremes. This is partly due to sample stations being selected for repeat hydrography dur-

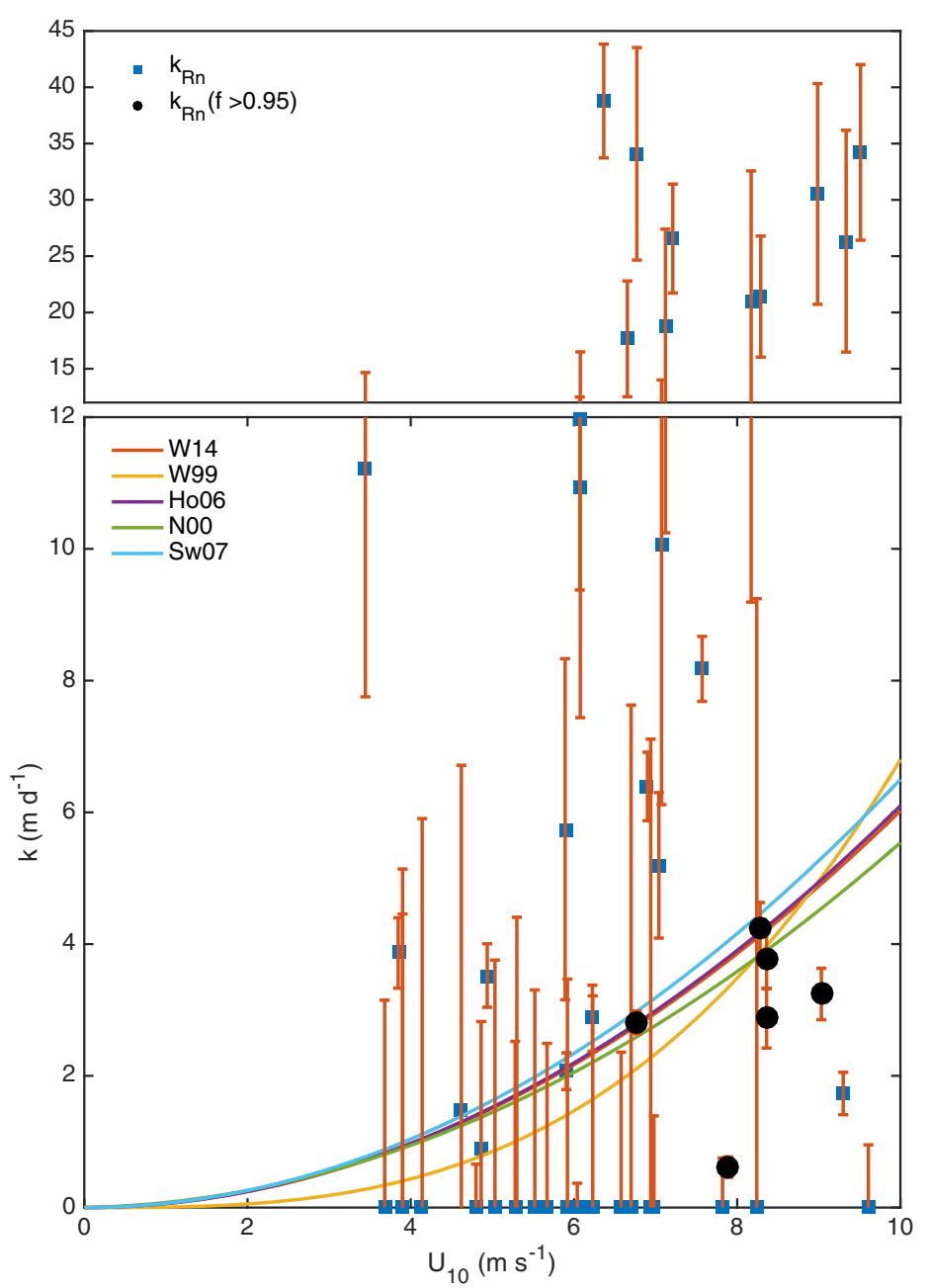

Figure 5. Wind speed from NCEP reanalysis weighted along 30 day time history starting from the date/time of the ${ }^{222} \mathrm{Rn}$ and ${ }^{226} \mathrm{Ra}$ profiles, and plot against the radon-deficit estimates of $k$, which are calculated using the radon-weighted time history of open water fraction in equation (5). ing this expedition and not chosen based upon the fraction of open water. This irregular sample coverage also reflects the observation that the marginal ice zone (with more intermediate values of $f$ ) extends over a relatively small area compared to the extrema; i.e., $0 \%$ or $100 \%$ open water.

Considering all 52 estimates from the three expeditions, the trend in $k_{\text {eff }}$ with the weighted fraction of open water ( $f$ ) reveals a general increase, from $\mathrm{f}=0$ to 1 -as ice cover decreases (Figure 4). However, small values of $f$ are also associated with nonzero gas transfer velocity: of the 29 values at $\mathrm{f}<0.1,12$ profiles yielded nonzero values of $k_{\text {eff, }}$ and the average of $k_{\text {eff }}$ below $\mathrm{f}<0.1$ was $0.57 \mathrm{~m} \mathrm{~d}^{-1}$. A linear fit between $k_{\text {eff }}$ and $\mathrm{f}$, produces a $y$ intercept of $0.53 \mathrm{~m} \mathrm{~d}^{-1}$ and a value of $2.3 \mathrm{~m} \mathrm{~d}^{-1}$ at $\mathrm{f}=1$. The correlation coefficient is low $(r=0.56)$, indicating a large degree of scatter. The individual uncertainties computed using equation (7) are expressed as error bars in Figures 4 and 5.

When $k$ is computed from $k_{\text {eff }}$ the reciprocals of small values of open water produce very 
large values of $k$ at low ice cover (Figure 4, right plot). If the linear fit between $k_{\text {eff }}$ and $f$ (blue line in Figure $5 a)$ is transformed into a relationship between $k$ and $f$ (red line in Figure 4, left plot), we find a trend, although with very large uncertainty, of increasing $k$ with increasing ice cover. This trend may imply that some kind of intensification happens in the open water between ice floes, leading to greater kinetics of gas transfer. A similar observation was made by Loose et al. [2009], based upon their measurements of gas transfer in a laboratory using variable ice cover and turbulent forcing. The results of Loose et al. [2016] also support this observation. However, the mathematical implication of equation (4) that as $\mathrm{f} \rightarrow 0, k \rightarrow \infty$ must be bounded by an upper limit. Instead, the limiting condition of $f=0$ may never be achieved in the real sea ice zone where Ekman and geostrophic flow continually act upon sea ice rheology to produce continuous openings and closings in the ice.

\subsection{Does Wind Speed Predict Air-Sea Gas Transfer in the Sea Ice Zone?}

It is a challenge to determine the best wind speed metric for comparison. Wind speed reanalysis data products show very low accuracy for estimating the instantaneous wind [Chaudhuri et al., 2014], but they are the only available data source that allows for wind estimates outside the brief space-time that is defined by the ship track. Using the JRA-55 wind speed reanalysis data and a land mask to remove land-based measurements, we determined the mean wind speed in the Arctic north of $60^{\circ} \mathrm{N}$ between 1979 and 2013 to be $4.91 \mathrm{~m} \mathrm{~s}^{-1}$ (Figure 6). Next, we interpolated the NCEP grid to match the positions of the shipboard underway wind speed time series from the JOIS 2013 and 2014 cruises (corrected from the anemometer height of $23 \mathrm{~m}$ to the $10 \mathrm{~m}$ reference level using a log-layer profile). The root-mean squared error (RMSE) between JRA-55 and the JOIS 2013 series was $7.4 \mathrm{~m} \mathrm{~s}^{-1}$ with the reanalysis wind biased low by $-1.39 \mathrm{~m} \mathrm{~s}^{-1}$ at $95 \%$ confidence. The NCEP reanalysis wind showed an RMSE of 5.73 and a bias of -1.4 at $95 \%$ confidence, compared with JOIS 2013 data. This is not an exhaustive comparison of reanalysis products such as that provided by Li et al. [2013], but it provides a metric by which we can judge the predictive quality of the wind speed data for estimating air-sea gas transfer velocity. Based upon this comparison, we have opted use the NCEP_Reanalysis 2 data provided by the NOAA/OAR/ESRL PSD, Boulder, Colorado, USA, (http://www.esrl. noaa.gov/psd/). The time and radon decay-weighted wind speed were computed using the weighting equation (A4) in the Appendix of Bender et al. [2011], similar to equation (8) above.

To compute the value of $k_{w s}$ predicted from the $10 \mathrm{~m}$ wind speed, we use the same empirical relationships that were used by Bender et al. [2011], with the exception that the update of Wanninkhof [1992], found in Wanninkhof [2014], has been used. The equations and references for each wind speed parameterization are found in Table 2. To evaluate the ability of the wind speed parameterization to predict the gas transfer velocity from radon-deficit profiles, we used the Chi-squared goodness of fit test,
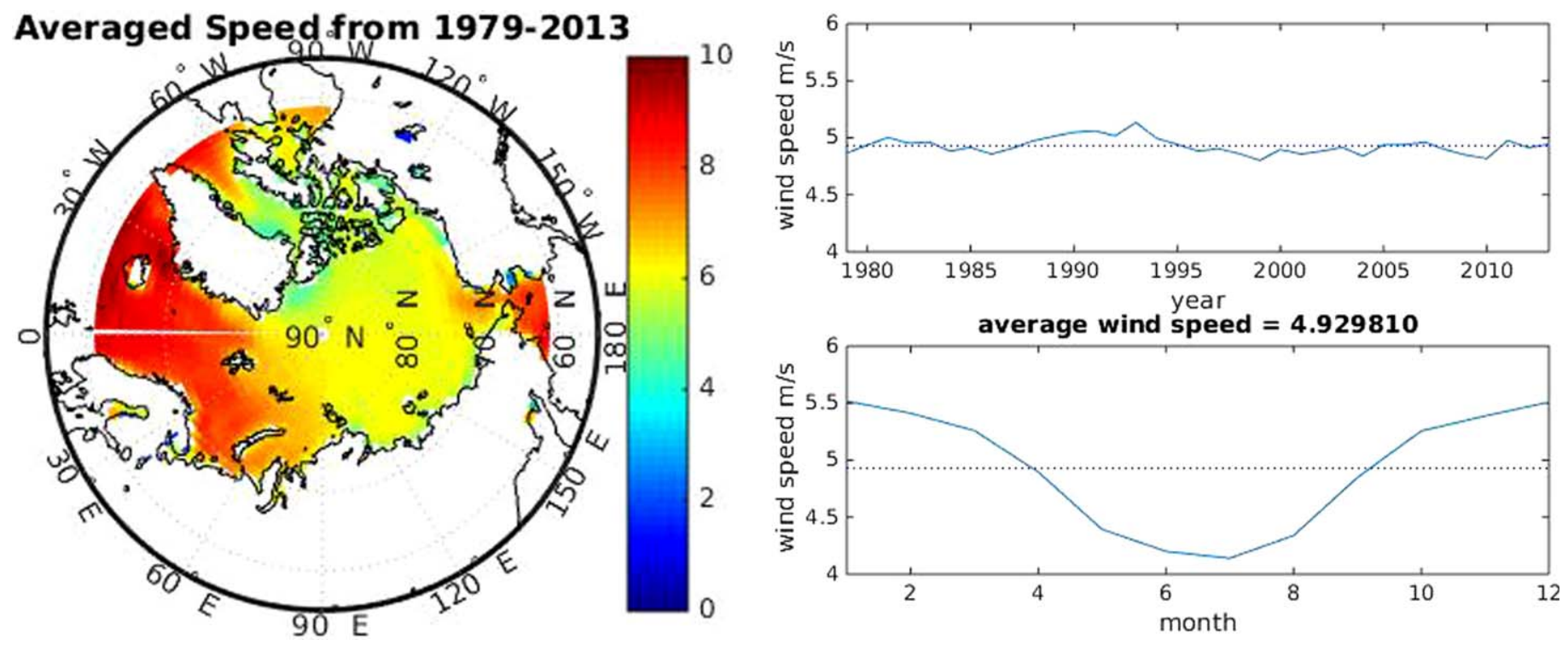

Figure 6. Wind speed climatology from the Japanese Reanalysis Data Project (JRA-55) for the Arctic Ocean, north of 60 N. 


$$
\chi^{2}=\sum_{i=1}^{N}\left(\frac{k_{i, R n}-k_{i, w s}}{k_{i, w s}}\right)^{2}
$$

where $k_{i, R n}$ and $k_{i, w s}$ are the observed transfer velocities from radon and the predicted transfer velocities from the wind speed parameterization. The critical value of $\chi^{2}$ is determined by $v=N-M$ degrees of freedom, where $N$ is the number of independent observations and $M$ is the number of parameters fit by the model [Press et al., 1992]. In this case, we assume a direct proportionality or slope of 1 to predict the relationship between $k_{i, R n}$ and $k_{i, w s}$, therefore $\mathrm{M}=1$.

Using all $N=52$ estimates of gas transfer from this study (JOIS 2013,14) and from RL14, $v=51$ and the likelihood that the values of $k_{i, R n}$ are described by the wind speed model at $95 \%$ confidence is bounded by $\chi_{C r}^{2} \leq 67.5$. None of the empirical relationships listed in Table 2 achieve this threshold; the best fit is that of Sweeney et al. [2007] $\left(\chi^{2}=784\right)$ and the worst fit comes from Wanninkhof and McGillis [1999] $\left(\chi^{2}=1876\right)$. Both predictions are more than an order of magnitude away from a suitable fit. If we removed the values where $k_{i, R n}$ predicted a zero gas exchange, because of secular equilibrium, this leaves $v=26$ degrees of freedom, and $\chi_{C r}^{2} \leq$ 38.9. With $k_{i, R n}=0$, the best fit is achieved by Sweeney et al. [2007], with a value of $\chi^{2}=290$, still far from an acceptable fit.

One other consideration impacting the fit quality is the impact of error and bias in the sea ice cover. Because the radon-deficit is a measure of $k_{\text {eff }}$, we must use equation (4) and an estimate of the fraction of open water $\left(f=1-\frac{S I C}{100}\right)$ to calculate $k$. When the percent sea ice cover approaches $100 \%$, dividing by $f$ significantly amplifies the estimate of $k$ as well the error in $k$ including that caused by the estimate of SIC (see section 3.1 for more detail). As noted in section 2.1.2, it can be difficult to obtain an accurate estimate of sea ice cover, especially in the marginal ice zone and close to $100 \%$ sea ice cover. High-resolution imagery often tends to reveal a nonzero fraction of open water even in nominally 100\% ice cover. Takahashi et al. [2009] used this line of reasoning in assuming that at least $10 \%$ open water exists at all times within the pack ice. While this may be an overestimate when ice cover is locally converging, it is apparent that existing estimates of satellite sea ice cover have at least 5\% uncertainty [Knuth and Ackley, 2006] near the high end. Taking these factors into account, we remove the estimates of $k$ where SIC $>95 \%$ and recompute Chi-squared fit test. This leaves $v=19$ and $\chi_{c r}^{2} \leq 30$. Again, the wind speed models do not come within an order of magnitude of the $\chi_{c r}^{2}$.

Based upon these three evaluations of the wind speed parameterizations, we conclude that wind speed is not an adequate predictor for $k$ in the vicinity of sea ice. However, a subset $(\mathrm{N}=6)$ of the radon profiles used in this analysis were collected at or near $f=1$ (100\% open water). Four of these profiles originate from RL14, and another two from this study (JOIS 2013, Station CB-29, $f=0.95$ and JOIS 2014, Sta-A, $f=0.98$ ). At $v=5, \chi_{C r}^{2} \leq 11$. In this case, all five of the empirical distributions yielded $\chi^{2}<2$ indicating acceptable fit to the estimates of $k$ from radon-deficit.

This subset of six relatively "open ocean" values reaffirms the results reported by [Bender et al., 2011] and RL14 that the time-weighted estimates of $10 \mathrm{~m}$ wind speed yield acceptable predictions of $k$ from radondeficit profiles. It further highlights the apparent contrast between processes driving the kinetics of gas transfer in the open ocean versus the processes in the ice zone where the wind speed parameterizations do not capture the forcing or the variability. The six estimates of $k$ in nearly ice-free conditions are called out with black circles in Figure 5.

We note that interpretation of the RL14 data set alone leads to a different interpretation, as compared with the combined data sets: RL14 find no measurable radon-deficit at both intermediate and low values of $f$ (i.e., $k_{\text {eff }}=0$ for $\mathrm{N}=14$ profiles at $\mathrm{f}<0.5$, Table 1 ). In comparison, the JOIS data found only nine values of $k_{\text {eff }}=0$ (within uncertainty) out of $\mathrm{N}=30$ profiles with $\mathrm{f}<0.5$. Based upon the ARK-XXVI data set, RL14 concluded that gas transfer appeared to be less than expected from a linear scaling with ice cover, which contrasts with our interpretation of the combined data sets. The apparent discrepancy might be explained by a number of possible processes, which we attempt to summarize here. Conditions during the ARK-XXVI may have led to mixed-layer deepening. This can be inferred in part from the increase in ice cover throughout the cruise [see Rutgers Van Der Loeff et al., 2014, Figure 1]. As we discussed in section 2.1.3, deepening of the mixed-layer will cause the ${ }^{222} \mathrm{Rn} /{ }^{226} \mathrm{Ra}$ activity ratio to move closer to its maximum of 1 , in a manner that does not reflect the equilibrium kinetics of air-sea gas exchange. Another possible explanation, may 
0
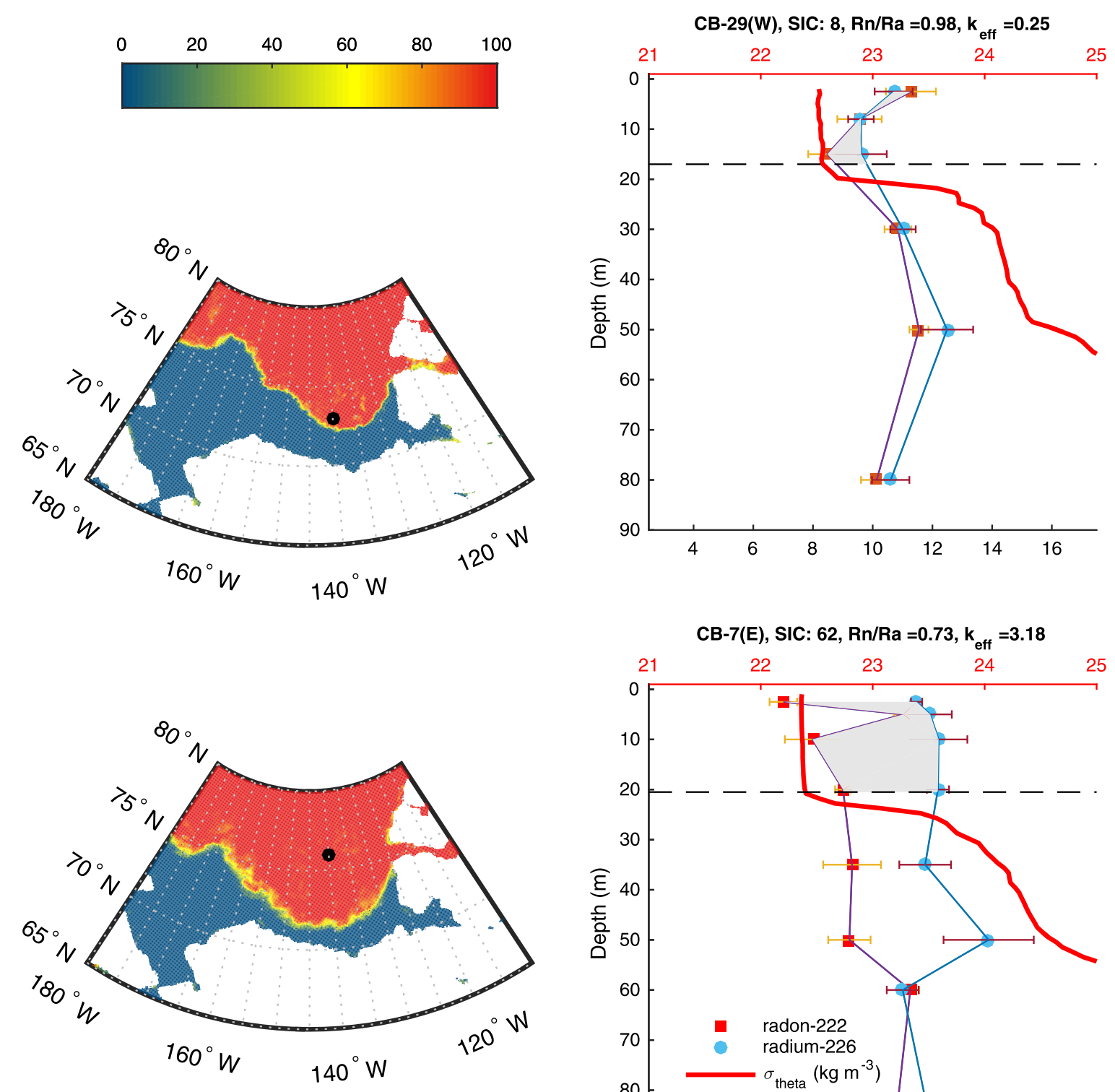

Figure 7. Radon-Radium profiles from two stations during JOIS 2014. Station CB-29 exhibits secular equilibrium up to the air-sea interface, even though the weighted ice cover at that

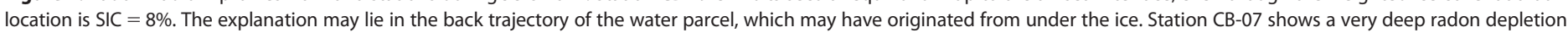
that does not fit with the high fraction of ice cover that was present. These stations both appear anomalous in Figure 4.

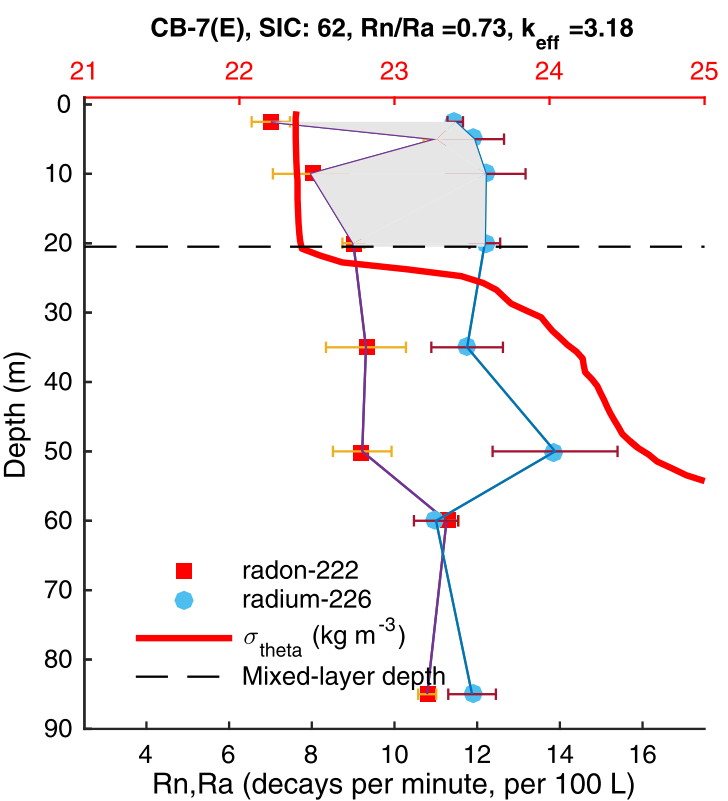

result from different ice conditions in the Central Arctic as compared to the Beaufort Sea; ice cover in the Beaufort may have been more fragmented with smaller floe size as a consequence of greater fetch conditions that can characterize that region [Smith and Thomson, 2016], as compared to the more consolidated ice conditions that characterize the nearly perennial ice cover that persists in the Central Arctic near the North Pole. Fragmented ice moves in free drift, driven by winds and currents, whereas more consolidated ice is also subject to the rheology of the ice pack itself. These differences in ice type may have led to differences in air-sea transfer kinetics [Hunke and Dukowicz, 1997]. Advection and Ekman velocity in the marginal ice zone, also make it challenging to accurately recover the time history of exposure and ice cover that a water parcel has experienced over the past 30 days. These processes are not easily predicted [Bigdeli et al., 2016], and they can lead to uncertainty as well as bias in the interpretation of gas transfer as a function of sea ice cover. 
We did not include the six estimates of $k_{\text {eff }}$ from FT91 in the statistical analysis, because we were unable to obtain the individual profiles of ${ }^{226} \mathrm{Ra}$ and ${ }^{222} \mathrm{Rn}$. Referring to Figure 4 in FT91, the profiles used to derive the largest values of $k_{\text {eff }}$ do not measure beneath the suspected mixed-layer, so no value of deep secular equilibrium could be confirmed. The values of FT91 stand out as larger than the more modern estimates, although the Arctic has changed significantly since that time. This is evident even in the mixed-layer depths reported by FT91, which revealed 60-100 m mixed-layers near the ice edge. These are deeper than mixedlayers observed today, even in winter [Cole et al., 2014], and may therefore imply that gas transfer in the past was greater than today as a consequence of changes in the stratification and freshwater of the surface ocean.

\section{Conclusions}

Using the $\mathrm{N}=52$ independent ${ }^{222} \mathrm{Rn} /{ }^{226} \mathrm{Ra}$ profiles from this study and from RL14, the mean transfer velocity in the modern Arctic sea ice zone was $k_{\text {eff }}=0.99 \mathrm{~m} \mathrm{~d}^{-1}$ across $\mathrm{f}=0.26$ open water fraction, yielding $k=4.0 \mathrm{~m} \mathrm{~d}^{-1}$ during wind conditions that are representative of the long-term average. The $10 \mathrm{~m}$ wind speed during JOIS 2013, 14 and RL14 was 5.4, 7.6, and $6.8 \mathrm{~m} \mathrm{~s}^{-1}$ as compared with the 1979-2013 NCEP average of $4.9 \mathrm{~m} \mathrm{~s}^{-1}+1.4 \mathrm{~m} \mathrm{~s}^{-1}$ of bias, or $6.3 \mathrm{~m} \mathrm{~s}^{-1}$. The average-weighted transfer velocity predicted by wind speed parameterization is $k_{\mathrm{ws}}=2.85 \mathrm{~m} \mathrm{~d}^{-1}$ [Wanninkhof, 2014], indicating that air-sea gas transfer predicted from radon-deficit profiles is larger than the wind speed scaling by $40 \%$.

This contrasts with the results based on the subset of stations presented before by Rutgers Van Der Loeff et al. [2014], illustrating the large variation in results, especially at intermediate ice cover. We therefore tested the statistical goodness of fit between $k$ and the transfer velocity using five wind speed parameterizations. The goodness of fit test was performed on the following data (sub)sets: (1) All $N=52$ radon-deficit profiles, (2) all profiles where $k>0$, (3) all profiles where $k>0$ and where $f>0.05$, and (4) all "open ocean" profiles where $f>0.95$. None of these sample subsets was adequately described using the wind speed parameterizations, except the "open ocean" radon-deficit profiles. The conclusion, therefore, is that wind speed adequately captures the estimate of $k$ using radon-deficit in the Arctic, when the water is nearly ice free. In contrast, the values of $k$ from within the marginal ice zone and the pack ice appear to be driven by other kinetics.

It is an open question whether we can better predict $k$ within the ice pack using other metrics of turbulence forcing. The process of weighting ice cover, wind speed, and mixed-layer depth (as well as buoyancy losses/ gains and ice-water relative velocity) is complicated by the Ekman-like flow in the surface ocean. A water parcel labeled with radon can drift along a trajectory that experiences variations in all these forcings [Cole et al., 2014]. Different mixed-layer depth horizons move at divergent speeds and trajectories to each other, such that the mixed-layer water column can have different forcing histories. We suspect that some of this variability is captured in the scatter of individual ${ }^{222} \mathrm{Rn} /{ }^{226} \mathrm{Ra}$ activity profiles (e.g., Figures 3 and 7). Regional models can provide detailed estimates of all these mixed-layer properties, but their fidelity to actual watercolumn properties renders their output to be little better than simple assumptions, such as ice-water velocity derived from Ekman flow [Bigdeli et al., 2016]. This topic is ripe for innovation to develop predictive solutions for estimating air-sea exchange in the ice zones of the ocean.

Acknowledgments

We gratefully acknowledge the insights and comments of two anonymous reviewers. We would like to thank the officers and crew of the Louis S. St. Laurent for two excellent scientific expeditions in the Arctic. We thank Andrey Proshutinsky for welcoming our participation in the BGOS expeditions, and gratefully acknowledge the help of Kris Newhall for logistical support to and from the Arctic. Funding was provided by the NSF Arctic Natural Sciences program through award 1203558. The new data presented in this study can be found at the Arctic Data Center (https:// arcticdata.io/metacat/d1/mn/v2/ object/arctic-data.9553.1).

\section{References}

Bates, N. R. (2006), Air-sea $\mathrm{CO}_{2}$ fluxes and the continental shelf pump of carbon in the Chukchi Sea adjacent to the Arctic Ocean, J. Geophys. Res., 111, C10013, doi:10.1029/2005JC003083.

Bender, M., S. Kinter, N. Cassar, and R. Wanninkhof (2011), Evaluating gas transfer velocity parameterizations using upper ocean radon distributions, J. Geophys. Res., 116, C02010, doi:10.1029/2009JC005805.

Bigdeli, A., B. Loose, and S. T. Cole (2016), Numerical investigation of the Arctic ice-ocean boundary layer: Implications for air-sea gas fluxes, Ocean Sci. Discuss., 2016, 1-41, doi:10.5194/os-2016-4.

Broecker, W. (1965), An application of natural radon to problems in ocean circulation, in Proc. Symp on Diffusion in Oceans and Fresh Waters, pp. 116-145, Palisades, New York.

Broecker, W., and T.-H. Peng (1971), The vertical distribution of radon in the BOMEX area, Earth Planet. Sci. Lett., 11, 99-108.

Butterworth, B. J., and S. D. Miller (2016), Air-sea exchange of carbon dioxide in the Southern Ocean and Antarctic marginal ice zone, Geophys. Res. Lett., 43, 7223-7230, doi:10.1002/2016GL069581.

Cassar, N., P. J. DiFiore, B. A. Barnett, M. L. Bender, A. R. Bowie, B. Tilbrook, K. Petrou, K. J. Westwood, S. W. Wright, and D. Lefevre (2011), The influence of iron and light on net community production in the Subantarctic and Polar Frontal Zones, Biogeosciences, 8, 227-237, doi:10.5194/bg-8-227-2011. 
Chaudhuri, A. H., R. M. Ponte, and A. T. Nguyen (2014), A comparison of atmospheric reanalysis products for the arctic ocean and implications for uncertainties in air-sea fluxes, J. Clim., 27(14), 5411-5421, doi:10.1175/JCLI-D-13-00424.1.

Cole, S. T., M.-L. Timmermans, J. M. Toole, R. A. Krishfield, and F. T. Thwaites (2014), Ekman veering, internal waves, and turbulence observed under Arctic Sea Ice, J. Phys. Oceanogr., 44(5), 1306-1328, doi:10.1175/JPO-D-12-0191.1.

Crabeck, O., B. Delille, S. Rysgaard, D. N. Thomas, N.-X. Geilfus, B. Else, and J.-L. Tison (2014), First "in situ" determination of gas transport coefficients $\left(\mathrm{DO}_{2}\right.$, DAr, and $\left.\mathrm{DN}_{2}\right)$ from bulk gas concentration measurements $\left(\mathrm{O}_{2}, \mathrm{~N}_{2}, \mathrm{Ar}\right)$ in natural sea ice, J. Geophys. Res. Oceans, 119 6655-6668, doi:10.1002/2014JC009849.

Delille, B., B. Jourdain, A. V. Borges, J.-L. Tison, and D. Delille (2007), Biogas ( $\mathrm{CO}_{2}$, $\mathrm{O}_{2}$, dimethylsulfide) dynamics in spring Antarctic fast ice, Limnol. Oceanogr., 52, 1367-1379.

Delille, B., et al. (2014), Southern Ocean $\mathrm{CO}_{2}$ sink: The contribution of the sea ice, J. Geophys. Res. Oceans, 119, 6340-6355, doi:10.1002/ $2014 J$ JC009941.

Edson, J. B., A. A. Hinton, K. E. Prada, J. E. Hare, and C. W. Fairall (1998), Direct covariance flux estimates from mobile platforms at sea, J. Atmos. Oceanic Technol., 15, 547-62.

Else, B., T. Papakyriakou, R. J. Galley, W. M. Drennan, L. A. Miller, and H. Thomas (2011), Wintertime $\mathrm{CO}_{2}$ fluxes in an Arctic polynya using eddy covariance: Evidence for enhanced air-sea gas transfer during ice formation, J. Geophys. Res., 116, C00G03, doi:10.1029/2010JC006760.

Fanning, K. A., and L. M. Torres (1991), ${ }^{222} \mathrm{Rn}$ and ${ }^{226} \mathrm{Ra}$ : Indicators of sea-ice effects on air-sea gas exchange, Polar Res., 10, 51-58.

Grosfeld, K., et al. (2016), Online sea-ice knowledge and data platform <www.meereisportal.de>, Alfred Wegener Inst. Polar Mar. Res. Ger. Soc. Polar Res., 85(2), 143-155, doi:10.2312/polfor.2016.011.

Heintzenberg, J., C. Leck, and P. Tunved (2015), Potential source regions and processes of aerosol in the summer Arctic, Atmos. Chem. Phys., 15, 6487-6502.

Ho, D. T., C. S. Law, M. J. Smitth, P. Schlosser, M. Harvey, and P. Hill (2006), Measurements of air-sea gas exchange at high wind speeds in the Southern Ocean: Implications for global parameterizations, Geophys. Res. Lett., 33, L16611, doi:10.1029/2006GL026817.

Ho, D. T., C. L. Sabine, D. Hebert, D. S. Ullman, R. Wanninkhof, R. C. Hamme, P. G. Strutton, B. Hales, J. B. Edson, and B. R. Hargreaves (2011a), Southern Ocean Gas Exchange Experiment: Setting the stage, J. Geophys. Res., 116, C00F08, doi:10.1029/2010JC006852.

Ho, D. T., R. Wanninkhof, P. Schlosser, D. S. Ullman, D. Hebert, and K. F. Sullivan (2011b), Towards a universal relationship between wind speed and gas exchange: Gas transfer velocities measured with ${ }^{3} \mathrm{He} \mathrm{SF}_{6}$ during the Southern Ocean gas exchange experiment, J. Geophys. Res., 116, C0OF04, doi:10.1029/2010JC006854.

Hunke, E. C., and J. K. Dukowicz (1997), An Elastic-viscous-plastic model for sea ice dynamics, J. Phys. Oceanogr., 27(9), 1849-1867, doi: 10.1175/1520-0485(1997)027<1849:AEVPMF>2.0.CO;2.

Kaiser, J., M. K. Reuer, B. Barnett, and M. L. Bender (2005), Marine productivity estimates from continuous $\mathrm{O}_{2} / \mathrm{Ar}$ ratio measurements by membrane inlet mass spectrometry, Geophys. Res. Lett., 32, L19605, doi:10.1029/2005GL023459.

Killawee, J. A., I. J. Fairchild, J.-L. Tison, L. Janssens, and R. Lorrain (1998), Segregation of solutes and gases in experimental freezing of dilute solutions: Implications for natural glacial systems, Geochim. Cosmochim. Acta, 62, 3637-3655.

Knuth, M., and S. F. Ackley (2006), Summer and early-fall sea-ice concentration in the Ross Sea: Comparison of in situ ASPeCt observations and satellite passive microwave estimates, Ann. Glaciol., 44, 303-309.

Li, M., J. Liu, Z. Wang, H. Wang, Z. Zhang, L. Zhang, and Q. Yang (2013), Assessment of Sea Surface Wind from NWP Reanalyses and Satellites in the Southern Ocean, J. Atmos. Oceanic Technol., 30(8), 1842-1853, doi:10.1175/JTECH-D-12-00240.1.

Liss, P. S. (1973), Processes of gas exchange across an air-water interface, Deep Sea Res., Part I, 20, 221-238.

Loose, B., and P. Schlosser (2011), Sea ice and its effect on $\mathrm{CO}_{2}$ flux between the atmosphere and the Southern Ocean interior, J. Geophys. Res., 116, C11019, doi:10.1029/2010JC006509.

Loose, B., W. R. McGillis, P. Schlosser, D. Perovich, and T. Takahashi (2009), The effects of freezing, growth and ice cover on gas transport processes in laboratory seawater experiments, Geophys. Res. Lett., 36, L05603, doi:10.1029/2008GL036318.

Loose, B., W. R. McGillis, D. Perovich, C. J. Zappa, and P. Schlosser (2014), A parameter model of gas exchange for the seasonal sea ice zone, Ocean Sci., 10, 17-28, doi:10.5194/os-10-17-2014.

Loose, B., A. Lovely, S. Peter, C. Zappa, W. McGillis, and P. Donald (2016), Currents and convection cause enhanced gas exchange in the icewater boundary layer, Tellus $B, 68,1-16$.

Luz, B., E. Barkan, M. L. Bender, M. H. Thiemens, and K. A. Boering (1999), Triple-isotope composition of atmospheric oxygen as a tracer of biosphere productivity, Nature, 400(6744), 547-550, doi:10.1038/22987.

Maslowski, W., B. Newton, P. Schlosser, A. Semtner, and D. Martinson (2000), Modeling recent climate variability in the Arctic Ocean, Geophys. Res. Lett., 27, 3743-3746, doi:10.1029/1999GL011227.

Mathieu, G. G., P. E. Biscaye, R. A. Lupton, and D. E. Hammond (1988), System for measurement of 222Rn at low levels in natural waters, Health Phys., 55, 989-992.

Morison, J., R. Kwok, C. Peralta-Ferriz, M. Alkire, I. Rigor, R. Andersen, and M. Steele (2012), Changing Arctic Ocean freshwater pathways, Nature, 481(7379), 66-70, doi:10.1038/nature10705.

Nicholson, D. P., R. H. R. Stanley, E. Barkan, D. M. Karl, B. Luz, P. D. Quay, and S. C. Doney (2012), Evaluating triple oxygen isotope estimates of gross primary production at the Hawaii Ocean Time-series and Bermuda Atlantic Time-series Study sites, J. Geophys. Res., 117, C05012, doi:10.1029/2010JC006856.

Nightingale, P. D., G. M. Malin, C. Law, A. Watson, P. S. Liss, M. I. Liddicoat, J. Boutin, and R. C. Upstill-Goddard (2000), In situ evaluation of air-sea gas exchange parameterizations using novel conservative and volatile tracers, Glob. Biogeochem. Cycles, 14, $373-387$.

Nomura, D., H. Eicken, R. Gradinger, and K. Shirasawa (2010), Rapid physically driven inversion of the air-sea ice $\mathrm{CO}_{2}$ flux in the seasonal landfast ice off Barrow, Alaska after onset of surface melt, Cont. Shelf Res., 30, 1998-2004, doi:10.1016/j.csr.2010.09.014.

Notz, D., and M. G. Worster (2009), Desalination processes of sea ice revisited, J. Geophys. Res., 114, C05006, doi:10.1029/2008JC004885.

Peng, T.-H., W. S. Broecker, G. G. Mathieu, and Y.-H. Li (1979), Radon evasion rates in the Atlantic and Pacific oceans as determined during the Geosecs program, J. Geophys. Res., 84, 2471-2486.

Petrich, C., and H. Eicken (2010), Growth, structure and properties of sea ice. In: Biogeochemistry of sea ice, in Sea Ice, edited by D. N. Thomas and G. S. Dieckmann, pp. 18,327-18,343, Wiley-Blackwell, Cambridge.

Press, W. H., S. A. Teukolsky, W. Vetterling, and B. Flannery (1992), Numerical Recipes in C: The Art of Scientific Computing, Cambridge Univ. Press, Cambridge, U. K.

Reuer, M. K., B. A. Barnetta, M. L. Bender, P. G. Falkowskib, and M. B. Hendricks (2007), New estimates of Southern Ocean biological production rates from $\mathrm{O}_{2} / \mathrm{Ar}$ ratios and the triple isotope composition of $\mathrm{O}_{2}$, Deep Sea Res., Part I, 54, 951-974.

Rutgers Van Der Loeff, M., N. Cassar, M. Nicolaus, B. Rabe, and I. Stimac (2014), The influence of sea ice cover on air-sea gas exchange estimated with radon-222 profiles, J. Geophys. Res. Oceans, 119, 2735-2751, doi:10.1002/2013JC009321. 
Rysgaard, S., R. N. Glud, M. K. Sejr, J. Bendtsen, and P. B. Christensen (2007), Inorganic carbon transport during sea ice growth and decay: A carbon pump in polar seas, J. Geophys. Res., 112, C03016, doi:10.1029/2006JC003572.

Rysgaard, S., J. Bendtsen, L. T. Pedersen, H. Ramlov, and R. N. Glud (2009), Increased $\mathrm{CO}_{2}$ uptake due to sea ice growth and decay in the Nordic Seas, J Geophys Res, 114, C09011, doi:10.1029/2008JC005088.

Smethie, W., T. Takahashi, D. Chipman, and J. Ledwell (1985), Gas Exchangeand $\mathrm{CO}_{2}$ Flux in the Tropical Atlantic Ocean Determined from

${ }^{222} \mathrm{Rn}$ and $\mathrm{pCO}_{2}$ measurements, J. Geophys. Res., 90, 7005-7022.

Smith, M., and J. Thomson (2016), Scaling observations of surface waves in the Beaufort Sea, Elementa (Wash D C), 4(97), 1-12.

Spreen, G., L. Kaleschke, and G. Heygster (2008), Sea ice remote sensing using AMSR-E 89-GHz channels, J. Geophys. Res., 113, C02S03, doi: $10.1029 / 2005 J C 003384$

Stanley, R. H. R., W. J. Jenkins, D. E. I. Lott, and S. C. Doney (2009), Noble gas constraints on air-sea gas exchange and bubble fluxes, J Geophys Res, 114, C11020, doi:10.1029/2009JC005396.

Sweeney, C., E. Gloor, A. R. Jacobson, R. M. Key, G. McKinley, J.-L. Sarmiento, and R. Wanninkhof (2007), Constraining global air-sea gas exchange for $\mathrm{CO}_{2}$ with recent bomb 14C measurements, Glob. Biogeochem. Cycles, 21, GB2015, doi:10.1029/2006GB002784.

Takahashi, T. et al. (2009), Climatological Mean and Decadal Change in Surface Ocean $\mathrm{pCO}_{2}$, and Net Sea-air $\mathrm{CO}_{2}$ Flux over the Global Oceans, Deep Sea Res., Part II, 56, 554-577.

Wanninkhof, R. (1992), Relationship between wind-speed and gas-exchange over the Ocean, J. Geophys. Res., 97, 7373-7382.

Wanninkhof, R. (2014), Relationship between wind speed and gas exchange over the ocean revisited, Limnol. Oceanogr. Methods, 12(6), 351-362, doi:10.4319/lom.2014.12.351.

Wanninkhof, R., and W. R. McGillis (1999), A cubic relationship between air-sea $\mathrm{CO}_{2}$ exchange and wind speed, Geophys. Res. Lett., 26, 1889-1892.

Zemmelink, H. J., J. W. H. Dacey, L. Houghton, E. J. Hintsa, and P. S. Liss (2008), Dimethylsulfide emissions over the multi-year ice of the western Weddell Sea, Geophys. Res. Lett., 35, L06603, doi:10.1029/2007GL031847.

Zhou, J., B. Delille, H. Eicken, M. Vancoppenolle, F. Brabant, G. Carnat, N.-X. Geilfus, T. Papakyriakou, B. Heinesch, and J.-L. Tison (2013), Physical and biogeochemical properties in landfast sea ice (Barrow, Alaska): Insights on brine and gas dynamics across seasons, J. Geophys. Res. Oceans, 118, 3172-3189, doi:10.1002/jgrc.20232. 